\title{
Regulators of ribonucleotide reductase inhibit Ty1 mobility in saccharomyces cerevisiae
}

\author{
John P O'Donnell ${ }^{1,2}$, Marie Gehman ${ }^{1,3}$, Jill B Keeney ${ }^{1 *}$
}

\begin{abstract}
Background: Ty1 is a long terminal repeat retrotransposon of Saccharomyces cerevisiae, with a replication cycle similar to retrovirus replication. Structurally, Ty1 contains long terminal repeat (LTR) regions flanking the gag and pol genes that encode for the proteins that enable Ty1 mobility. Reverse transcriptase produces Ty1 complementary (c)DNA that can either be integrated back into the genome by integrase or recombined into the yeast genome through homologous recombination. The frequency of Ty1 mobility is temperature sensitive, with optimum activity occurring at $24-26^{\circ} \mathrm{C}$.

Results: In this study, we identified two host genes that when deleted allow for high temperature Ty1 mobility: RFX1 and SML1. The protein products of these genes are both negative regulators of the enzyme ribonucleotide reductase, a key enzyme in regulating deoxyribonucleotide triphosphate (dNTP) levels in the cell. Processing of Ty1 proteins is defective at high temperature, and processing is not improved in either $r f x 1$ or $5 m / 1$ deletion strains. Ty 1 mobility at high temperature is mediated by homologous recombination of Ty 1 CDNA to Ty1 elements within the yeast genome. We quantified cDNA levels in wild type, $r f x 1$ and $s m / 1$ deletion background strains at different temperatures. Southern blot analysis demonstrated that cDNA levels were not markedly different between the wild type and mutant strains as temperatures increased, indicating that the increased Ty1 mobility is not a result of increased cDNA synthesis in the mutant strains. Homologous recombination efficiency was increased in both $r f \times 1$ and $s m / 1$ deletion strains at high temperatures; the $r f \times 1$ deletion strain also had heightened homologous recombination efficiency at permissive temperatures. In the presence of the dNTP reducing agent hydroxyurea at permissive temperatures, Ty1 mobility was stimulated in the wild type and $5 \mathrm{~m} / 1$ deletion strains but not in the $r f \times 1$ deletion strain. Mobility frequency was greatly reduced in all strains at high temperature. Deletion of the S-phase checkpoint pathway Dun1 kinase, which inactivates $S \mathrm{ml} 1$ and Rfx1, reduced Ty1 mobility at a range of temperatures.
\end{abstract}

Conclusions: Levels of cellular dNTPs, as regulated by components of the S-phase checkpoint pathway, are a limiting factor in homologous recombination-mediated Ty1 mobility.

\section{Background}

Managing genome stability is a complex process, requiring a delicate balance of gene structure and sequence integrity with flexibility for genetic exchange and DNA repair. The Ty1 long terminal repeat (LTR) retrotransposons of Saccharomyces cerevisiae inevitably play a major role in this balance, because the yeast genome contains $\sim 30$ whole length elements and hundreds of LTR sequences. The genes gag and pol contained within Ty1 elements encode for structural proteins and enzymatic

\footnotetext{
* Correspondence: keeney@juniata.edu

'Department of Biology, Juniata College, Huntingdon, PA, USA

Full list of author information is available at the end of the article
}

proteins, respectively. As in related retroviruses, the gag domain encodes for the structural protein coat of the virus-like particle (VLP) and the pol region consists of essential enzymatic proteins (protease, reverse transcriptase and integrase) that mediate Ty1 mobility events [1]. Ty1 elements are transcribed from the genome into mRNA which accounts for up to $0.8 \%$ of total cellular RNA [2]. The Ty mRNA is then translated and processed via a protease, which is encoded by the pol region of Ty1. Post processing, reverse transcriptase and integrase are active, and continue the life cycle through synthesis of complementary (c)DNA from the mRNA template and integration of the Ty cDNA into the genome.
Ciomed Central

C 2010 O'Donnell et al; licensee BioMed Central Ltd. This is an Open Access article distributed under the terms of the Creative Commons Attribution License (http://creativecommons.org/licenses/by/2.0), which permits unrestricted use, distribution, and reproduction in any medium, provided the original work is properly cited. 
Incorporation of cDNA into the host genome can occur by $R A D 52$-dependent homologous recombination (HR) or integrase-mediated integration; the term Ty1 mobility is used to describe these collective integration events.

Ty1 mobility is a temperature sensitive mechanism that occurs optimally at $20-26^{\circ} \mathrm{C}$. Levels of Ty1 mobility are drastically reduced when yeast cells are grown at or above $32^{\circ} \mathrm{C}$, even though cellular growth is unaffected [3]. Thus, an unknown regulatory mechanism has evolved to repress Ty1 mobility as temperature increases. We have previously analysed various steps of the Ty1 life cycle at a range of temperatures. At high temperatures (above $34^{\circ} \mathrm{C}$ ), processing by protease of the Ty1 Gag-Pol-p199 polyprotein into structural and enzymatic protein domains is blocked, thus gag processing is partially inhibited and processing of integrase is completely inhibited. Additionally, reverse transcriptase activity is dampened within VLPs, and Ty1 cDNA cannot be detected by Southern blot analysis. The mechanism of Ty1 mobility shifts as the temperature increases. At permissive temperatures, the primary integration mechanism is integrase mediated; however, the relatively few high temperature mobility events are mediated by homologous recombination of Ty1 cDNA.

Ty1 mobility, regardless of mechanism, is tightly regulated by host cell factors. Ty1 mRNA is very abundant, yet transposition of endogenous Ty1 occurs at a very low level [4]. Several groups have conducted genomewide screens, identifying numerous host factors that mediate regulation of Ty1 mobility at many steps in the life cycle of the element [5-10]. To investigate the mechanism of temperature regulation of Ty1, we were specifically interested in determining the mechanism by which host cell factors limit Ty1 mobility at high temperatures. In this study, we screened a yeast deletion library for increased transposition at high temperatures $\left(34^{\circ} \mathrm{C}\right)$. We found that deletion of RFX1, SML1 or GRH1 resulted in increased levels of Ty1 mobility at high temperatures. Interestingly, Sml1 and $\mathrm{Rfx} 1$ are both negative regulators of ribonucleotide reductase (RNR), which catalyzes the rate-limiting step in deoxyribonucleotide triphosphate (dNTP) synthesis. In yeast, the RNR enzyme is composed of a large homodimeric subunit originating from the $R N R 1$ gene plus a small heterodimeric subunit derived from the RNR2 and RNR4 genes. RFX1 (also known as CRT1) is the predominant regulator of the $R N R 2, R N R 3$ and $R N R 4$ genes. The sequence specific transcriptional repressor $\mathrm{Rfx} 1$ protein binds to DNA damage response elements (X boxes) located within the promoter region of the RNR genes, and recruits general repressors. [11-13]. The Sml1 protein regulates RNR activity by binding and inhibiting the RNR1 homodimeric subunit $[14,15]$. Thus, deletion of either SML1 or RFX1 results in an increase in intracellular dNTP pools [16-18]. RFX1 has been previously identified as a marginal regulator of Ty1 mobility [7]. In this study, we have identified $S M L 1$ as a novel regulator of Ty1 transposition.

Regulation of dNTP concentration is crucial during the $S$ phase of the cell cycle. Low concentrations of dNTPs can lead to replication fork stalling and potential collapse, whereas high concentrations of dNTPs can result in polymerase infidelity, leading to mutations. Consequently, RNR activity is regulated at multiple levels: transcriptionally by $\mathrm{Rf} x 1$, post-translationally by Sml1 and allosterically by dNTPs, especially dATP $[11,18,19]$. Control of Sml1 and Rfx1 activity are tightly linked to S-phase and the S-phase checkpoint pathways (Figure 1). Sml1 is normally degraded during S-phase to provide dNTP substrates for DNA synthesis [20]. Additionally, activation of the S-phase checkpoint pathway in response to DNA damage or stalled replication forks leads to an increase in RNR activity [20]. Activation of the S-phase checkpoint begins with binding of the sensor complex to affected DNA in response to either replication blocks or pauses. The sensor complex recruits the essential kinase Mec1. A mediator kinase (either Mrc1 for replication pauses or Rad9 for replication blocks) is then phosphorylated, which subsequently activates the effector kinase Rad53. [21-27]. The activated Rad53 kinase activates Dun1, which in turn phosphorylates and subsequently inactivates Rfx1 and Sml1. [11,12,18,28,29]. The resulting increase in $R N R$ gene transcription and active RNR protein provides the increased levels of dNTPs necessary to a cell dealing with replication problems [30].

Several host factors linking Ty1 mobility to S-phase checkpoint pathways and genome stability have been identified [7,10]. Recently, Curcio et al. characterized mutations in a set of repressor of Ty1 transposition $(r t t)$ genes [31]. They showed that mutations in S-phase checkpoint pathways increase Ty1 mobility in 19 rtt mutants involved in genome stability. These rtt mutations play a role in the S-phase Rad53 effector pathway, separate from dNTP regulation. Although mobility of Ty1 elements does not require S-phase checkpoint proteins, the observation that Ty1 activation is mediated by an increase in Ty1 protein levels and reverse transcriptase activity in rtt101 mutants suggests that Ty1 mobility is an integral part of the DNA damage response $[31,32]$. Indeed, Ty1 has been shown to play a role in repair of chromosomal lesions [32,33].

To understand how increased dNTP levels in sml1 and $r f \times 1 \Delta$ (deletion) mutants relate to increased Ty 1 mobility, we investigated multiple steps within the Ty lifecycle. We quantified transposition and cDNA levels in wild type, $r f x 1 \Delta$ and sml1s strains at varying temperatures. Southern blot analysis demonstrated that cDNA levels did not differ between the wild type and mutant strains as temperature increases, indicating that 


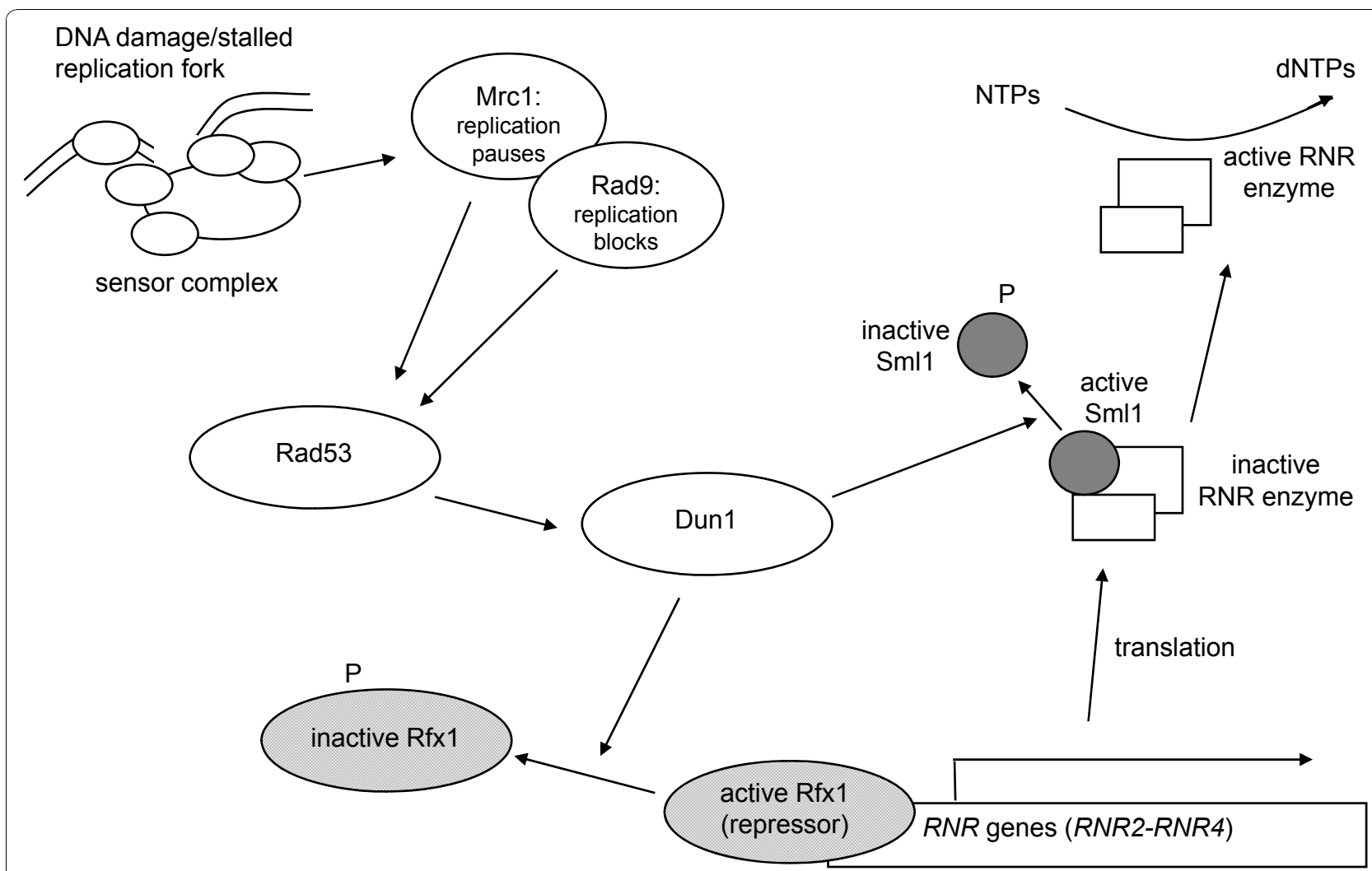

Figure 1 Schematic of the ribonucleotide reductase (RNR) induction pathway. DNA damage or stalled replication forks during S-phase activates a sensor complex that recruits Mec1 to the site. Mec1 then activates a mediator kinase; either Mrc1 at stalled replication forks, or Rad9 at damaged sites. The activated mediator kinase then activates the effector kinase Rad53, which subsequently phosphorylates Dun1. The activated Dun1 protein phosphorylates the transcriptional repressor Rfx 1 (Crt1), thereby inactivating it and allowing for increased transcription of the RNR genes. Sml1 binds and keeps inactive the large RNR1 subunit; Dun1 phosphorylation of Sml1 causes it to release RNR1, and the enzyme becomes active. RNR converts NTPs to dNTPs as needed for DNA synthesis and repair. Only the pathway components most relevant to this

study are shown.

increased Ty1 mobility is not a result of increased cDNA synthesis in the deletion strains. Homologous recombination efficiency was increased in both $r f \times 1 \Delta$ and smll $\Delta$ strains at high temperatures, suggesting that the increased mobility results from increased homologous recombination of Ty1 cDNA. Mobility assays were also conducted in the presence of the dNTP reducing agent, hydroxyurea (HU), which eliminated the high temperature phenotype in both $r f x 1 \Delta$ and $\operatorname{sml} l \Delta$ strains. Our results show that dNTP concentrations are a limiting resource for Ty1 mobility at high temperatures.

\section{Results}

\section{Genetic screen for regulators of high temperature transposition}

Ty1 transposition is temperature sensitive, mainly due to inactivity of the protease enzyme and reduction of protein levels at high temperatures [3]. To study specific host regulation of transposition, we screened a yeast deletion library for mutants that transpose under high temperature conditions of $34^{\circ} \mathrm{C}$ [34]. An aliquot of the $M A T a$ deletion pool was transformed with a galactoseinducible Ty1 element (pGTy1) marked with his $3 A I$ on plasmid pGTy1H3mhis3AI [35]. With this plasmid, transposition is assayed by plating cells onto a medium containing galactose to induce transposition, followed by plating to a medium lacking histidine to select for Ty1 mobility. Upon splicing and subsequent reverse transcription of the his3AI marker gene, a functional HIS3 gene sequence can be incorporated into the yeast genome, either by integration via the Ty1 integrase or by recombination by the host cellular machinery. The resulting His-positive papillae are collectively referred to as pGTy1 mobility events, because this assay cannot distinguish between integration and recombination. pGTy1H3mhis3AI transformants of a MATa deletion pool were induced on galactose medium at $34^{\circ} \mathrm{C}$ and subsequently screened for growth on synthetic complete medium lacking histidine (SC-His) at levels higher than background colonies. Putative high temperature clones 
were then screened in a secondary patch assay. Nine final clones were isolated, and the deleted open reading frames (ORFs) were identified by PCR and sequencing. The nine final clones included three each with deletions of the genes SML1, RFX1/CRT1 and GRH1. Rfx1 and Sml1 are both involved in regulation of the RNR enzyme, which converts NTPs to dNTPs for DNA synthesis and repair. Grh1 is a cis-Golgi localized protein involved in endoplasmic reticulum to Golgi transport[36]. This study focused on the role of Sml1 and Rfx1 in Ty1 mobility.

The transposition level of each deletion strain was assayed using a quantitative mobility assay (Figure 2; Additional file 1). There was a slight increase in mobility in the mutant strains at permissive temperatures. As the assay temperature increased, mobility decreased in all strains, but dropped faster in the wild type strain. The difference in pGTy1 mobility in the mutant strains was two-fold to 10 -fold above wild type at $34^{\circ} \mathrm{C}$.

\section{The high temperature mobility phenotype is strain specific and is not additive}

The yeast deletion mutant strains have been shown to contain secondary mutations that affect phenotypic screens [37]. To ensure that the high temperature phenotype was a direct effect of the originally deleted mutation, fresh LEU2 deletions were constructed for each mutation in yeast strain Hansen BY4741. These strains were transformed with plasmid pGTy1his3AI[ $\Delta 1]$ and assayed for transposition; these strains maintained the high temperature transposition phenotype (data not shown). We also wanted to test whether double deletion strains showed a stronger high temperature transposition phenotype. Pairwise combinations of genes disrupted with the kanmx4 or LEU2 marker genes were constructed, transformed with pGTy1his3AI $[\Delta 1]$, and assayed for pGTy1 mobility at permissive and high temperatures $\left(34^{\circ} \mathrm{C}\right)$. We found that although the level of transposition in the double mutants always matched the phenotype of the individual mutation with the strongest high temperature phenotype, the double deletion strains were not additive (data not shown). This is not unexpected given the precise regulation of RNR activity and the inhibition of cell cycle progression by constitutively high dNTP levels $[19,38]$. There is likely to be a carefully regulated threshold level of dNTPs, so that removal of one or two regulatory measures is compensated for by other means.

We also constructed deletion mutations for each gene in yeast strain JKc1011, which originates from the GRF167 background. This strain shows consistently higher levels of transposition as compared with the

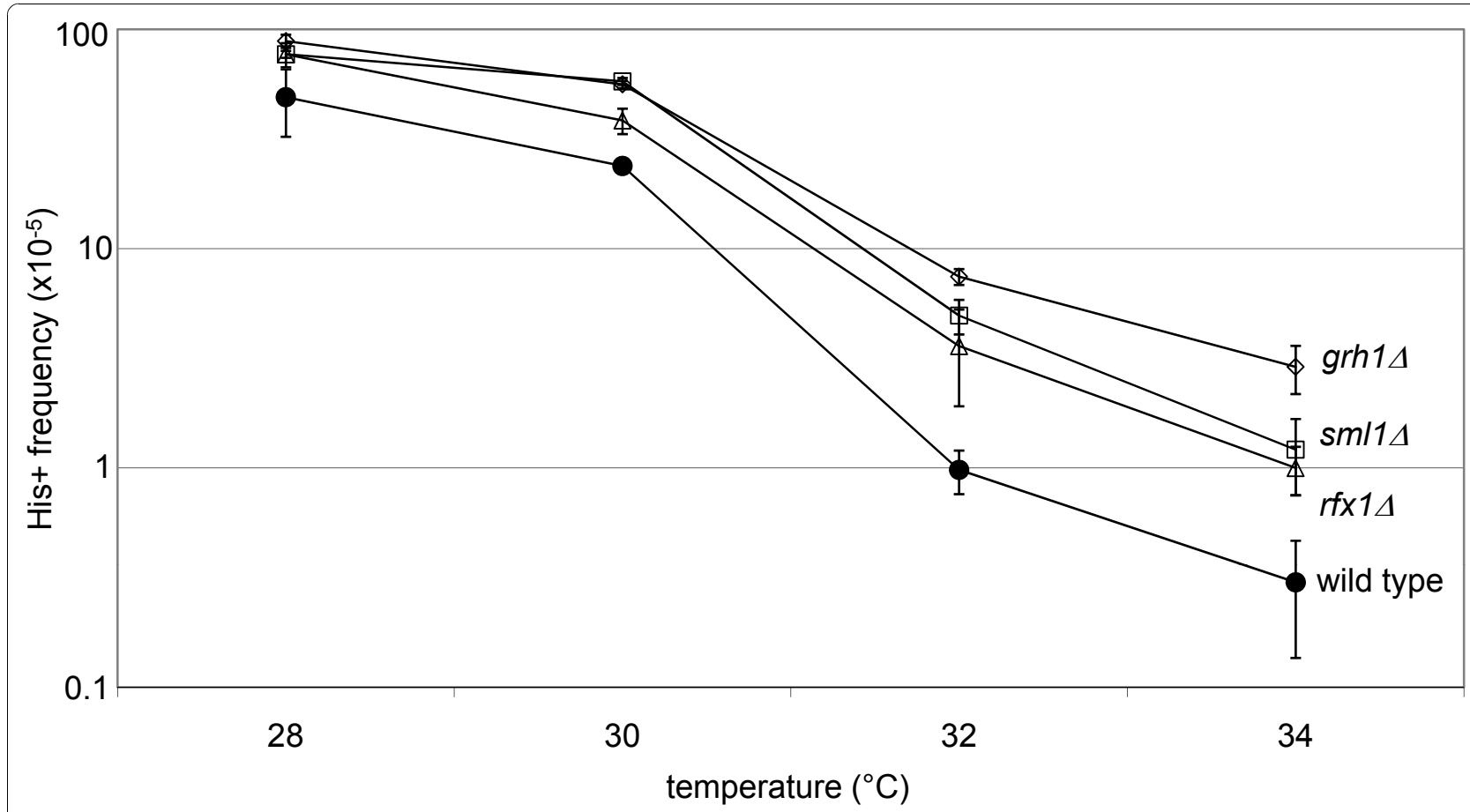

Figure 2 Deletion mutants show increased Ty1 mobility at high temperature. Isogenic wild type and mutant deletion strains were assayed for pGTy1 mobility at $28,30,32$ and $34^{\circ} \mathrm{C}$. Black circles indicate wild type (JKC1356), open squares are sm/1 $\Delta$ (JKc1357); open triangles are ifx $1 \Delta$ (JKc1358); open diamonds are grh1 $\Delta$ (JKc1359). The mutant strains show higher levels of pGTy1 mobility compared with wild type. Each point represents the average of three measurements; error bars indicate the standard deviation. See Additional file 1 for numerical values. 
yeast deletion strain Hansen BY4741 [8]. In patch assays, the GRF167-derived deletion strains did not demonstrate a high temperature mobility phenotype as compared with the wild type strain (data not shown). Thus, the temperature effect of these deletion mutations is strain specific.

\section{Protein processing not affected in mutant strains}

Processing of Ty 1 translation products by the Ty 1 encoded protease is an ordered process, essential for efficient transposition of the Ty1 element [39]. The primary Gag translation product is cleaved to produce the capsid protein, the structural component of VLPs. The Gag-Pol translation product is cleaved by protease into capsid, protease, integrase and reverse transcriptase. We previously showed that protease processing of the GagPol polyprotein is defective at high temperatures [3]. Thus, we investigated processing of the Ty1 Gag and Pol proteins in wild type and the $r f x 1 \Delta$ and smll $\Delta$ mutant strains. Strains containing the pGTylhis3AI[ $\Delta 1]$ plasmid were induced by galactose in liquid medium at permissive $\left(26^{\circ} \mathrm{C}\right)$ and high $\left(34^{\circ} \mathrm{C}\right)$ temperatures; extracts of protein from aliquots removed at 0,6 and 12 hours of induction were separated by SDS-PAGE and immunoblotted using a polyclonal antiserum to Gag or a monoclonal antibody to Pol. A polyclonal serum to glyceraldehyde-3-phosphate dehydrogenase (Gadph) was used as a loading control.

The Gag antiserum detects the primary Gag-p49 translation product and the subsequent processed Gagp45 capsid product. No Gag protein products were detectable before galactose induction (Figure 3). Gagp49 and Gag-p45 were both detectable after 6 hours of galactose induction in all strains at $26^{\circ} \mathrm{C}$ (Figure 3, left) and $34^{\circ} \mathrm{C}$ (Figure 3, right). The ratio of Gag-p49 to the processed Gag-p45 product did not vary with strain genotype or temperature after 6 hours of induction. Thus, it is unlikely that the deletion mutants affect processing of the Gag protein.

The monoclonal antibody $8 \mathrm{~B}-11$ detects the primary, unprocessed Gag-Pol-p199 polyprotein, several processing intermediates, and the processed $71 \mathrm{kD}$ integrase (pol-p71) (Figure 4). The processed integrase was undetectable in extracts from cells induced at high temperature (Figure 4, right) consistent with our previous data Although processing of the integrase protein at $26^{\circ} \mathrm{C}$ appeared to be more efficient in both the $r f x 1 \Delta$ and $\operatorname{sml} 1 \Delta$ deletion strains compared with wild type (Figure 4, left), neither of the mutant strains had detectable processed integrase at $34^{\circ} \mathrm{C}$ (Figure 4, right). Thus, the mutant strains have no detectable effect on the processing of the Ty1 Gag-Pol-p199 at high temperatures.

\section{Dependence of high temperature mobility phenotype on recombination}

As described above, Ty1 mobility refers to integration or recombination events. We have shown previously that recombination events represent a fraction of events at permissive temperatures and that the fraction of events resulting from recombination increases as the temperature increases [8]. Recombination-mediated and integration-mediated transposition events can be distinguished by assaying for Ty1 mobility in the absence of RAD52, which is required for homologous recombination [40]. Thus, mobility assays conducted in strains containing a rad52 mutation will only yield integrase-mediated events. We constructed rad52 deletions in each of the mutant strains and quantified pGTy1 mobility levels. The high temperature $\left(34^{\circ} \mathrm{C}\right)$ phenotype of the $r f x 1 \Delta$ strain was RAD52 dependent (Figure 5; Additional file 2), indicating that the high temperature pGTy1 mobility in this strain occurred via recombination. However, the increased pGTy1 mobility seen in the sml1A strain at 32 and $34^{\circ} \mathrm{C}$ appeared to be due to integrasemediated transposition events, as the difference in mobility between the $\mathrm{rad} 52$ and $\mathrm{rad} 52 \operatorname{sml} 1 \Delta$ strains was similar to the difference in mobility between the wild type and $\operatorname{sml} 1 \Delta$ strain.

\section{Ty1 cDNA levels are not increased in $r f x 1 \Delta$ and sml1 mutants}

In the $r f x 1 \Delta$ and $\operatorname{sml} 1 \Delta$ mutants, the high temperature phenotype is probably primarily due to recombination, and processing of the Gag-Pol protein remains defective. These results suggest that the increase in Ty1 mobility at high temperatures in $r f x 1 \Delta$ and $\operatorname{sml} l \Delta$ mutants is due to increased recombination of Ty1 cDNA. It is plausible that the increase in intracellular dNTPs could stimulate reverse transcriptase to produce relatively more $\mathrm{Ty} 1$ cDNA or that the efficiency of homologous recombination is increased.

To test the first possibility, we compared Ty1 cDNA levels in wild type and deletion strains by hybridizing SphI-digested DNA with a probe to the Ty1 Pol gene region (Figure 6A) [7]. This probe hybridized to both plasmid and genomic sequences and resulting cDNAs (Figure 6A). The pGTy1his3AI[ $\Delta 1]$ Ty1 plasmid, which is present in high copy, was detected as a prominent band at $3.1 \mathrm{kbp}$. pGTy1 cDNA from galactose induction of cells containing the plasmid was detected as a faint band at $2.6 \mathrm{kbp}$. Endogenous Cellular recombination efficiency in wild type and deletion strains.

Ty1 cDNA was the lowest molecular weight band on the Southern blot, at $1.7 \mathrm{kbp}$. The probe also hybridized to molecular weight fragments of varying sizes derived from genomic Ty1 elements. The $2.6 \mathrm{kbp}$ pGTy1-derived 


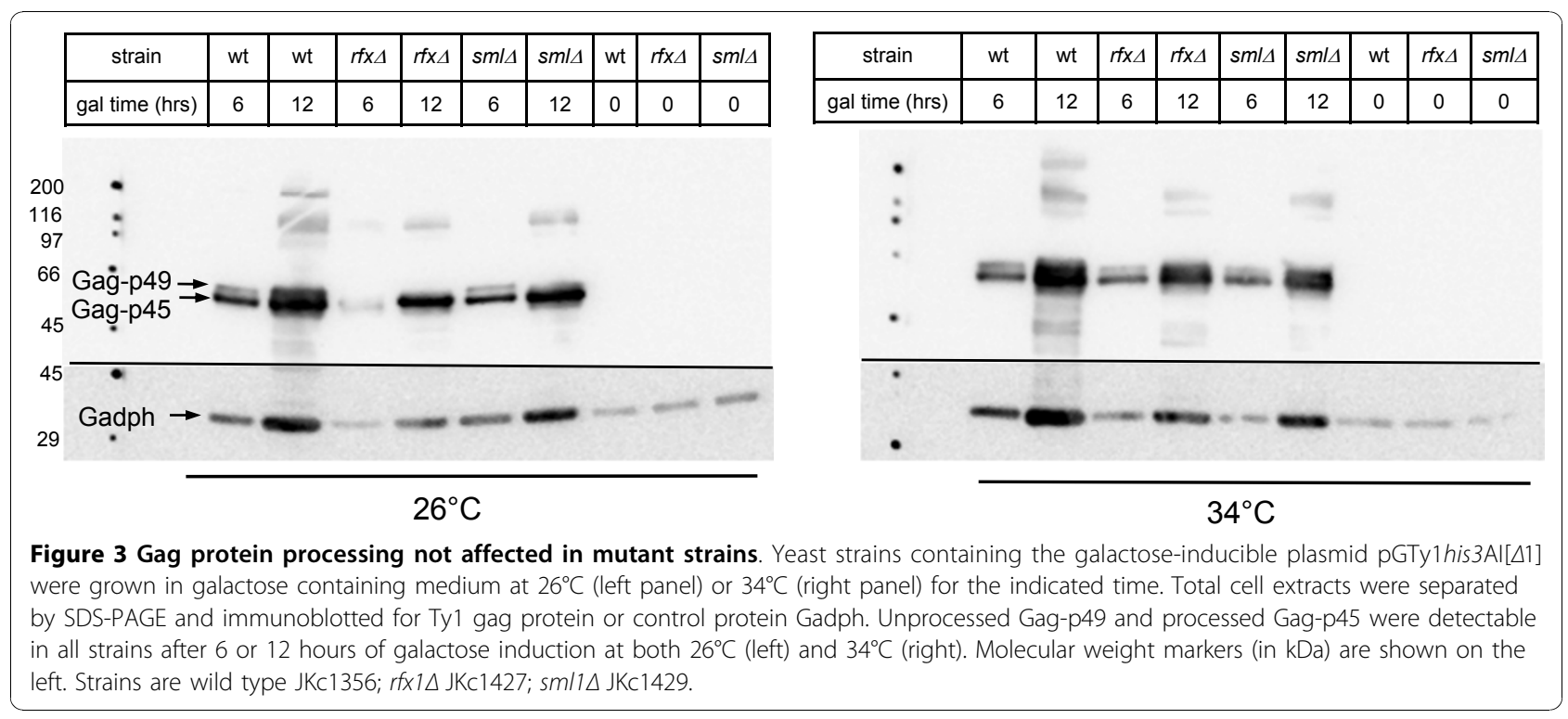

cDNA, although faint, appeared to mirror the expression pattern of the $1.7 \mathrm{kbp}$ Ty1 cDNA. The endogenous cDNA was readily visible in all strains at $30^{\circ} \mathrm{C}$, but barely visible at $34^{\circ} \mathrm{C}$.

Endogenous Ty1 cDNA levels were quantified by normalizing to genomic Ty bands (Figure 6, G1 and G2). The relative change in cDNA with temperature variation was determined by normalizing to the signal at $30^{\circ} \mathrm{C}$ within each strain (Table 1). As expected, as temperature increased, the level of cDNA dropped; at $34^{\circ} \mathrm{C}$ the level of cDNA was reduced to about one-tenth of the levels at $30^{\circ} \mathrm{C}$. We also compared cDNA levels between strains at each temperature by normalizing to wild type
cDNA levels (Table 1). No difference in cDNA level was seen between the wild type and deletion strains at each temperature, with the notable exception of the decreased level of cDNA in the $r f x 1 \Delta$ strain at $26^{\circ} \mathrm{C}$. Thus, the increase in pGTy1 mobility at high temperature is not due to an increase in cDNA levels in the $r f \times 1 \Delta$ and sml1s strains.

The dramatic decrease in Ty 1 cDNA in the $r f \times 1 \Delta$ mutant at $26^{\circ} \mathrm{C}$ is unexpected. (Figure 6). It should be noted that for detection of endogenous cDNA, strains are routinely grown at $20^{\circ} \mathrm{C}$ [31]. However, in $r f \times 1 \Delta$ strains grown at $20^{\circ} \mathrm{C}$, endogenous cDNA was undetectable by Southern blot analysis (data not shown). The

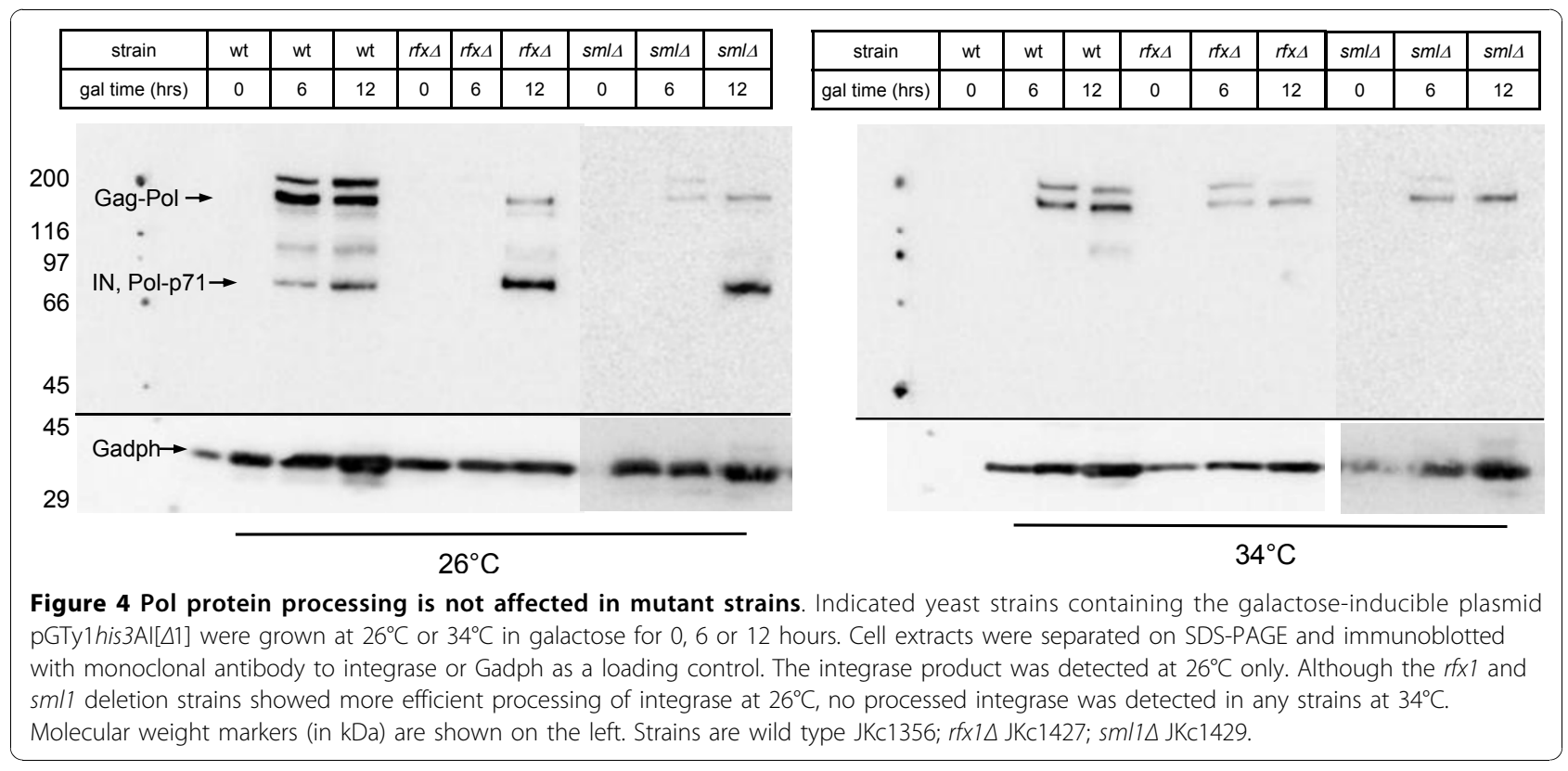




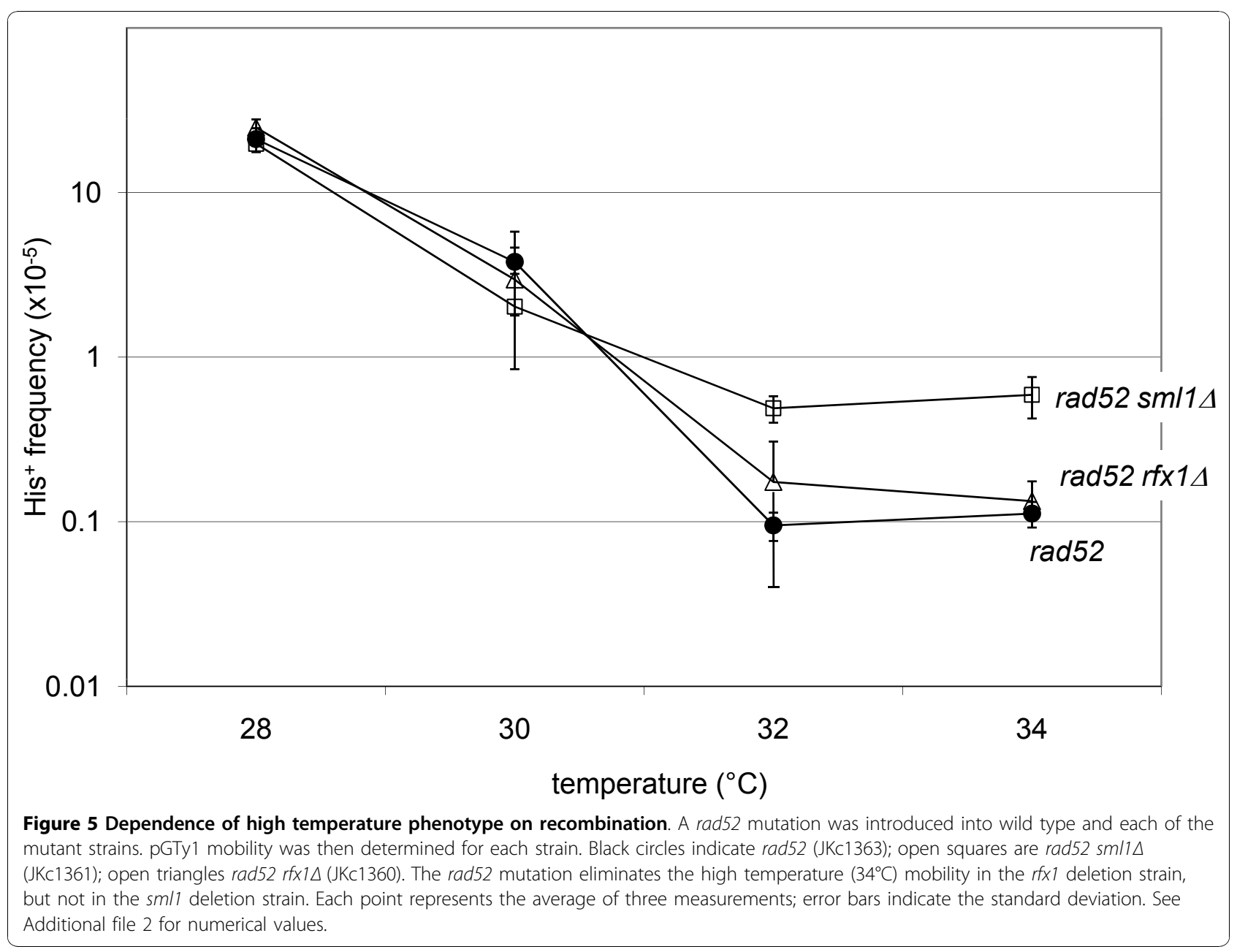

reduction of Ty1 cDNA in the $r f x 1 \Delta$ strain at low temperatures indicates that the $r f \times 1 \Delta$ strain may be cold sensitive [41]. We assayed transposition in the $r f \times 1 \Delta$ mutant at cold temperatures and found that transposition was only slightly reduced compared with wild type at $15^{\circ} \mathrm{C}$, and was identical to wild type at $20^{\circ} \mathrm{C}$ (data not shown). We conclude that very low levels of cDNA, although undetectable by Southern blot analysis, are sufficient to yield measureable pGTy1 mobility in a patch assay.

\section{Cellular recombination efficiency in wild type and deletion strains}

Ty1 cDNA levels are not increased in $\operatorname{sml1\Delta }$ and $r f \times 1 \Delta$ mutant strains at high temperatures. Thus, we hypothesized that if increased cellular dNTPs in the deletion mutants mimic the DNA repair response, homologous recombination activity may be increased in these strains, thus the available Ty1 cDNA would be more efficiently recombined in the mutant strains, resulting in increased activity in the Ty1 mobility assay. We assayed cellular recombination using a modified gap-repair assay [8]. A PCR product spanning the deleted region of the his $3 \Delta 1$ allele was transformed into competent yeast cells that were grown and transformed at 30 and $34^{\circ} \mathrm{C}$. Repair of the his $3 \Delta 1$ deletion by homologous recombination to the PCR product results in formation of histidine prototrophs, and the homologous recombination efficiency is calculated as the number of histidine prototrophs per cells transformed. This ratio is then multiplied by a transformation efficiency factor determined by transforming a HIS3 2-micron plasmid. A schematic of the assay and the results are shown in Figure 7 . At $30^{\circ} \mathrm{C}$, homologous recombination in the $r f x 1 \Delta$ mutant was increased by more than five-fold compared with wild type, and homologous recombination in the $s m l 1 \Delta$ mutant was comparable with wild type. At $34^{\circ} \mathrm{C}$, both deletion strains had an increase in recombination compared with the wild type. The $r f \times 1 \Delta$ deletion strain increased by 13 -fold and the sml1 strain by around threefold (Figure 7B, C). Transformation efficiency was adjusted for cell number. The transformation efficiency 
A.

plasmid: $3.1 \mathrm{kbp}$

pGTy1 cDNA: $2.6 \mathrm{kbp}$

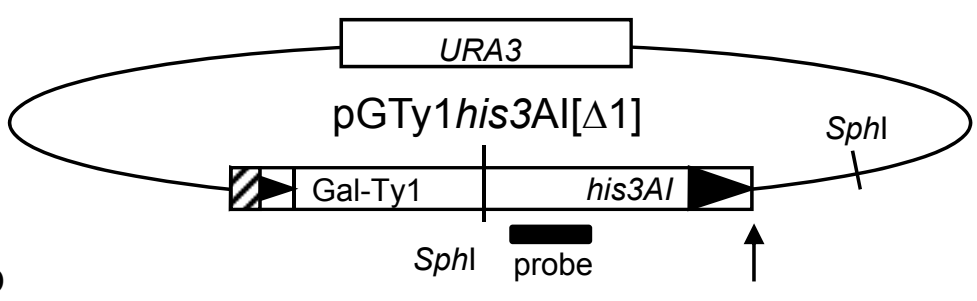

(Sphl site in Ty to end of cDNA)

end of cDNA

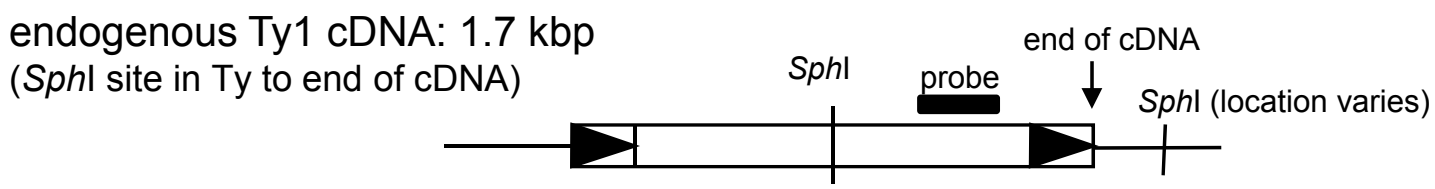

\section{chromosomal elements: variable}

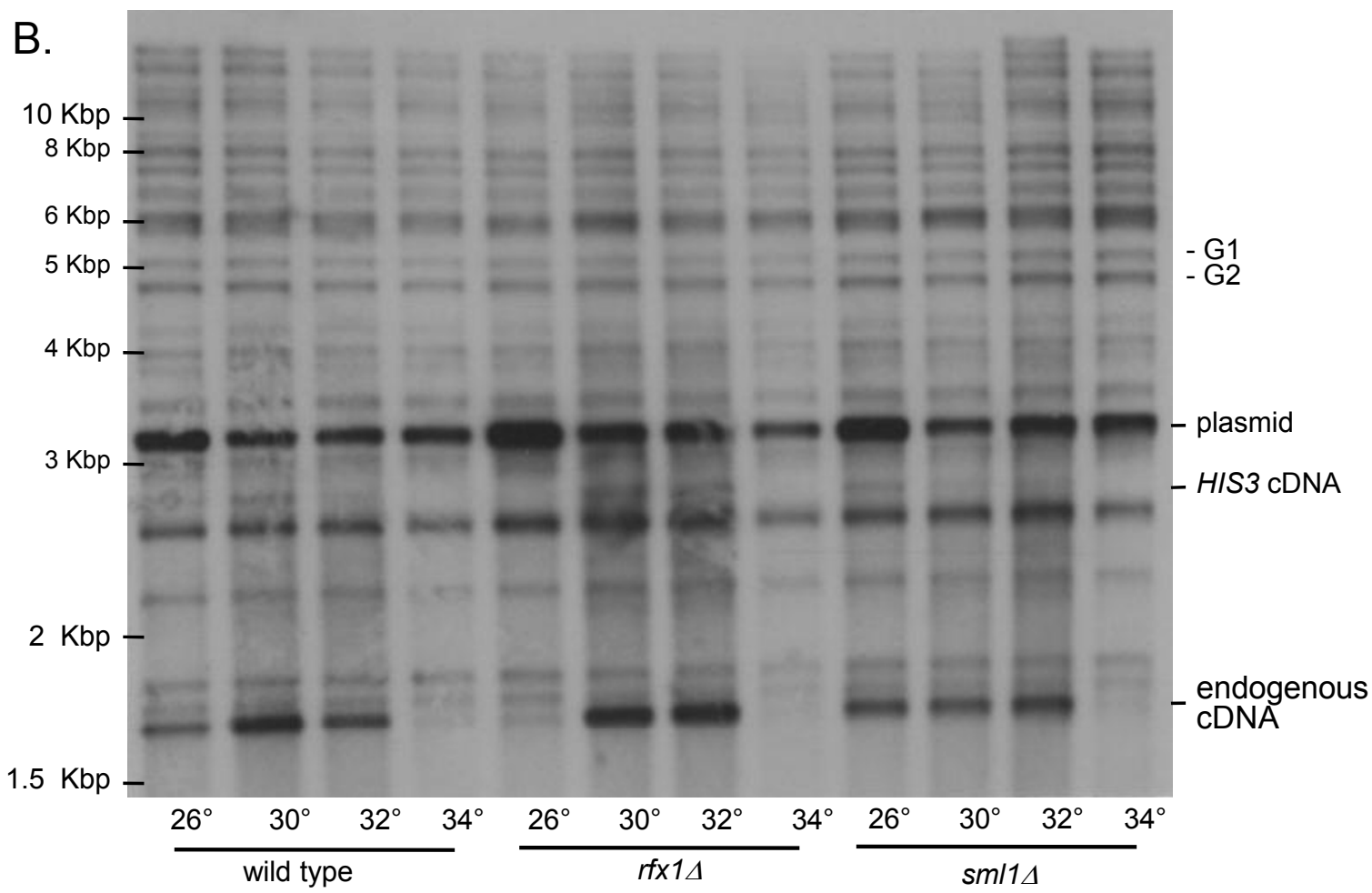

Figure 6 Ty1 complementary (c)DNA levels in wild type and mutant yeast strains. Total genomic DNA was isolated from each strain, digested with Sphl, transferred to nitrocellulose and probed for Pol sequences. (A) Diagram and expected size (in kbp) of Ty1 sequences detected by the Pol probe (modified with permission [31]). Sphl sites are indicated by thin vertical lines and regions hybridizing to the Pol probe are shown as black rectangles. Ty1 LTR sequences are represented as black triangles; the hatched box on the plasmid represents the galactoseinducible promoter.(B) Autoradiogram of the Southern blot. Strains and temperature of galactose induction $\left({ }^{\circ} \mathrm{C}\right)$ are indicated below the blot. The locations of the pGTy1 and Ty1 sequences detected by the Pol probe are indicated on the right; the locations of molecular size standards are indicated on the left. The endogenous Ty1 cDNA signal in each lane was normalized to the genomic bands G1 and G2. The ratio of cDNA signal relative to $30^{\circ} \mathrm{C}$ within each strain and the ratio of CDNA relative to wild type between strains is given in table 1. Strains are as follows: wild type JKc1356; rfx1 JKC1427; sm/14 JKc1429. 
Table 1 Relative cDNA levels in wild type and mutant strains

\begin{tabular}{lcccccccccccc}
\hline & \multicolumn{3}{c}{ Wild type } & \multicolumn{1}{c}{$\boldsymbol{r f x} \mathbf{1 \Delta}$} & \multicolumn{3}{c}{$\boldsymbol{s m I \Delta}$} \\
\hline Temperature, ${ }^{\circ} \mathrm{C}$ & 26 & 30 & 32 & 34 & 26 & 30 & 32 & 34 & 26 & 30 & 32 & 34 \\
\hline Fraction of $30^{\circ} \mathrm{C}$ & 0.66 & 1 & 0.72 & 0.09 & 0.12 & 1 & 1.14 & 0.1 & 0.51 & 1 & 0.78 & 0.07 \\
\hline Fraction of wild type & 1 & 1 & 1 & 1 & 0.16 & 0.88 & 1.4 & 0.95 & 1.09 & 1.41 & 1.53 & 1.02 \\
\hline
\end{tabular}

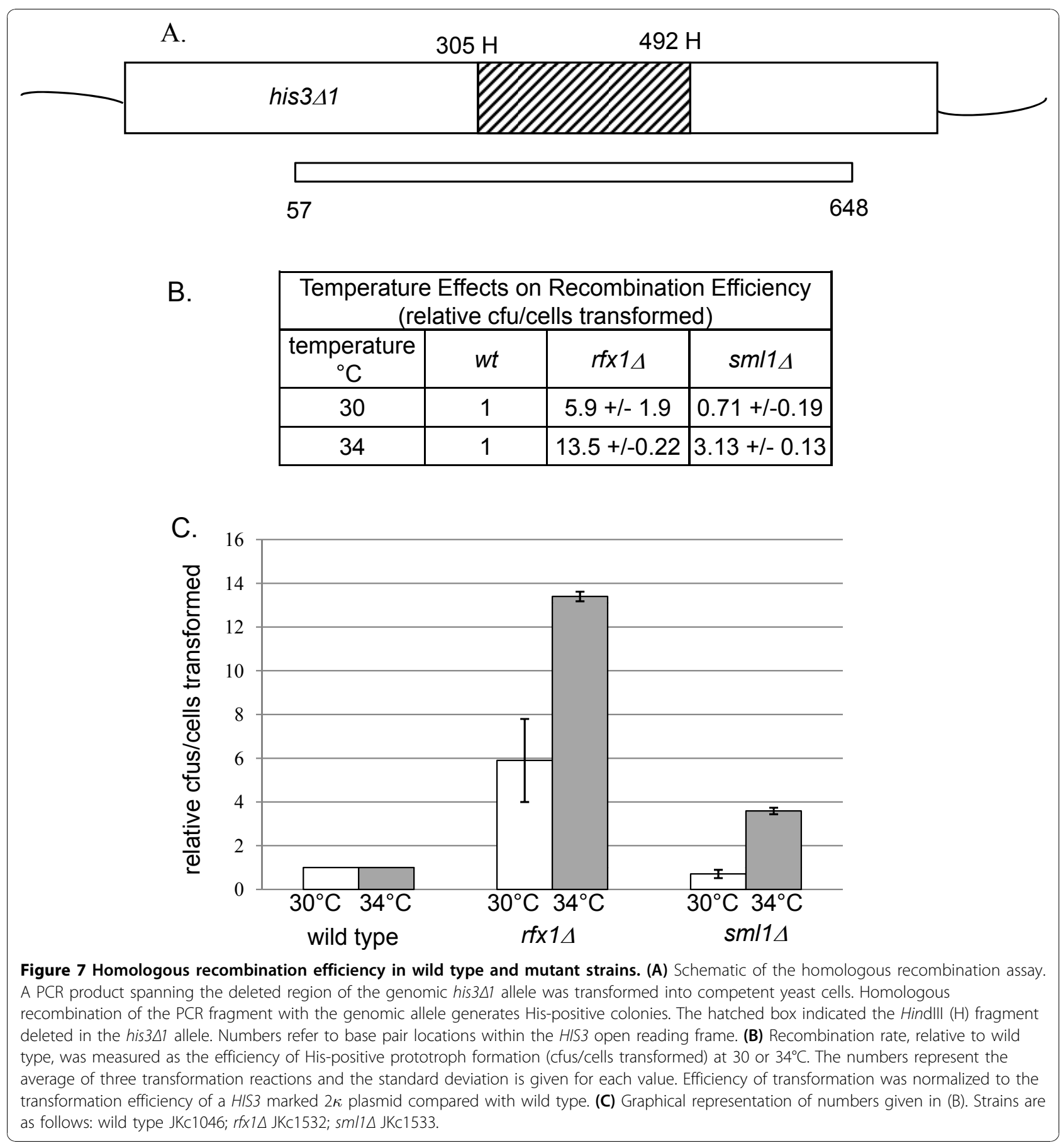


of the 2-micron plasmid was reduced in $r f x 1 \Delta$ cells, especially at $30^{\circ} \mathrm{C}$. The reason for this is unknown.

\section{Effects of $\mathrm{HU}$ on transposition}

We propose that the increase in dNTP levels in $r f x 1 \Delta$ and sml1 $1 \Delta$ strains increases the HR efficiency of Ty1 cDNA, resulting in increased pGTy1 mobility at high temperature. Thus, we predict that pGTy1 mobility at high temperature would decrease if dNTPs are limited. We used the RNR inhibitor HU to decrease the cellular levels of dNTPs. In yeast, HU impedes DNA synthesis and limits the expansion of dNTP pools above basal levels during G1/S phase [42]. Interestingly, it has previously been shown that treatment with $\mathrm{HU}$ elevates Ty1 cDNA levels and endogenous Ty1 mobility at per-

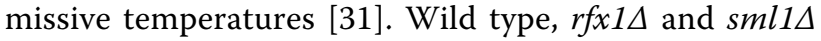
deletion strains containing plasmid pGTy1his3AI[ $\Delta 1]$ were induced in galactose medium without or with $\mathrm{HU}$. We found that in the presence of HU, pGTyl mobility at $28^{\circ} \mathrm{C}$ (permissive temperature) increased modestly (two to three times) in both the wild type and sml1s strains, but there was no induction of pGTy1 mobility in the $r f x 1 \Delta$ strain (Figure 8A; Additional file 3). pGTy1 mobility in the presence of $\mathrm{HU}$ at high temperature was measured using a patch assay. pGTy1 mobility decreased with increasing concentration of $\mathrm{HU}$, and the presence of HU eliminated the high temperature transposition phenotype in both $\operatorname{sml1\Delta }$ and $r f x 1 \Delta$ strains (Figure 8B). Attempts to quantify transposition at $34^{\circ} \mathrm{C}$ (high temperature) in the presence of $\mathrm{HU}$ did not yield adequate His-positive events to be analyzed quantitatively. This result supports the conclusion that dNTP concentrations are a limiting resource for pGTy1 mobility at high temperatures.

\section{Effects of DUN1 on Ty1 mobility}

We wondered whether altering the activity of proteins upstream in the S-phase checkpoint pathway would have an effect on Ty1 mobility. Phosphorylation of Sml1 and Rfx 1 by Dun1 releases the repressive effects of these regulators (Figure 1). Thus, overexpression of Dun1 might be expected to increase RNR activity through inactivation of Rfx1 and Sml1, resulting in increased dNTP pools and a concomitant increase in Ty1 mobility at high temperature. Conversely, deletion of Dun1 would mean that Sml1 and Rfx1 would retain their suppressive activity, so that RNR is not activated. Thus, we would expect a decrease in cellular dNTP pools, resulting in a decrease in the Ty1 high temperature mobility phenotype.

A high copy LEU2 $2 \mu$ plasmid containing the DUN1 gene was transformed into a yeast strain containing the galactose inducible plasmid pGTy1his3AI[ $\Delta 1]$. Transformants were then assayed for transposition at 32 and $34^{\circ}$ C. Overexpression of Dun1 had no effect on pGTy1 mobility (data not shown). The plasmid pGTylhis3AI $[\Delta 1]$ was also transformed into a dun $1 \Delta$ strain and assayed for transposition at $26,28,30$ and $32^{\circ} \mathrm{C}$ using a patch assay. As predicted, deletion of Dun1 decreased pGTy1 mobility compared with wild type across the range of temperatures (Figure 9), which is consistent with an integration of the S-phase checkpoint pathway into regulation of Ty1 mobility.

\section{Discussion}

Retroelements are regulated by hundreds of host proteins that integrate into numerous cellular pathways [9]. A curious aspect of $\mathrm{Ty} 1$ regulation is the temperature sensitivity of the retro-element; Ty1 mobility decreases rapidly with increasing temperature, even though cell growth is not impaired. We have shown previously that a defect in Ty1 protease at high temperatures $\left(34-35^{\circ} \mathrm{C}\right)$ results in a lack of processed integrase and a reduction in reverse transcriptase activity [3]. As a result, the mechanism of Ty1 mobility shifts from integrasemediated to HR-mediated as temperature increases [8]. Correspondingly, it has been shown that Ty1 cDNA is used for homologous recombination at permissive temperatures when integrase function is blocked [40]. In this study, we found that deletion of either of the RNR negative regulators, Sml1 or Rfx1, increased pGTy1 mobility, especially at high temperatures. Our results show that the pGTy1 mobility increase in $r f x 1 \Delta$ and sml1 $\Delta$ mutants at $34^{\circ} \mathrm{C}$ is due to an increase in cellular HR efficiency, probably mediated by an increase in cellular dNTP levels. Importantly, other studies have quantified dNTP levels in yeast, and have shown a twofold to fivefold increase of dNTP concentrations in $r f x 1 \Delta$ and sml14 strains [16,17].

\section{Increased Ty1 mobility mediated by increased}

\section{homologous recombination, not Ty1 protein activity}

Ty1 mobility can be regulated at multiple steps of the retroviral lifecycle, including protein processing, cDNA production and cDNA integration. We investigated each of these steps and determined that the increase in pGTy1 mobility in $r f x 1$ and sml1 deletion strains is due to increased efficiency in HR of Ty1 cDNA. We previously showed that Ty1 protein processing is less efficient at high temperatures [3]. Thus, we investigated protein processing of $g a g$ and pol proteins in the $r f \times 1 \Delta$ and sml1 $\Delta$ strains. Although processing of the $71 \mathrm{kDa}$ integrase protein was more efficient at $26^{\circ} \mathrm{C}$ in the deletion strains, none of the strains have detectable $71 \mathrm{kDa}$ integrase at $34^{\circ} \mathrm{C}$; the processing of Gag did not differ between wild type and mutant strains (Figure 3, Figure 4). Thus, the increase in pGTy1 mobility in $r f x 1$ and sml1 deletion strains at high temperature is not the result of an increase in Ty1 protein expression or processing. 


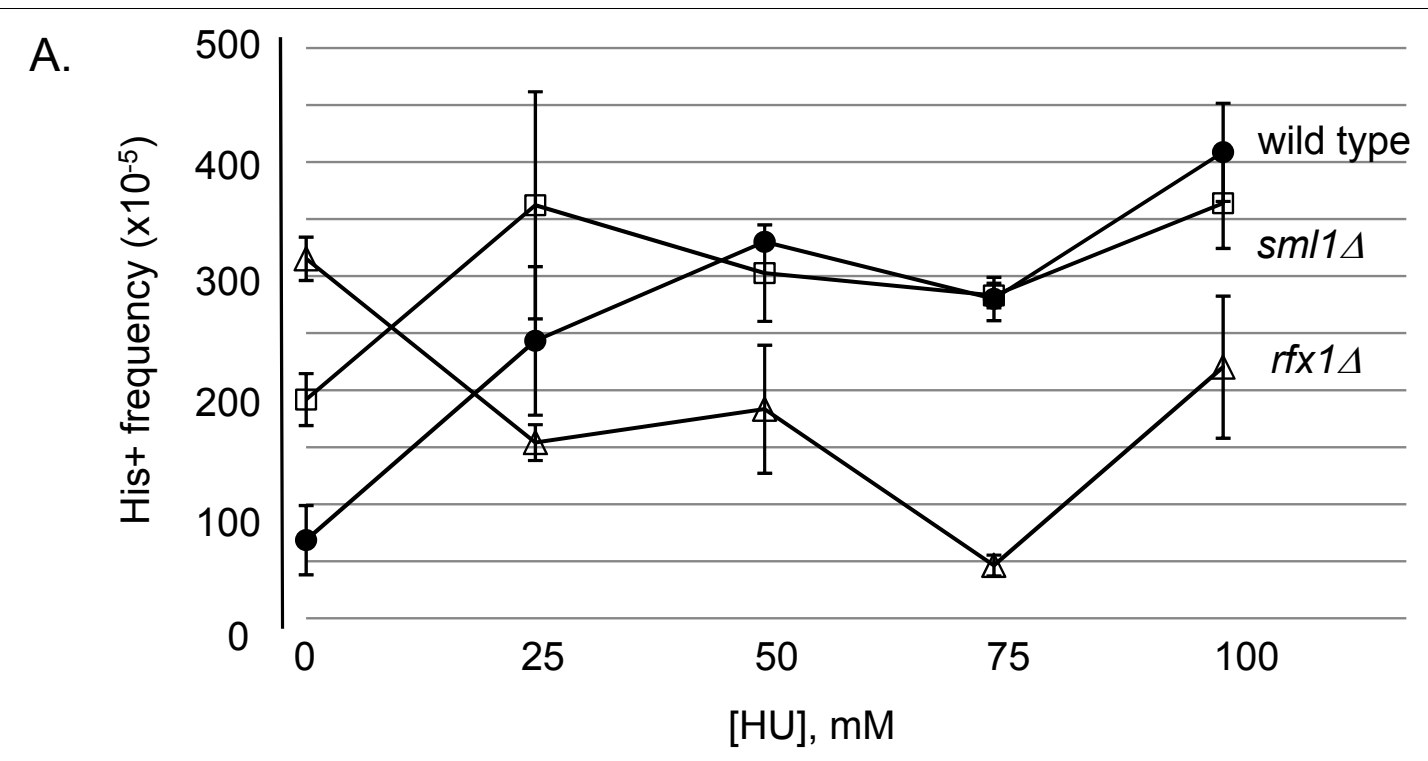

B.

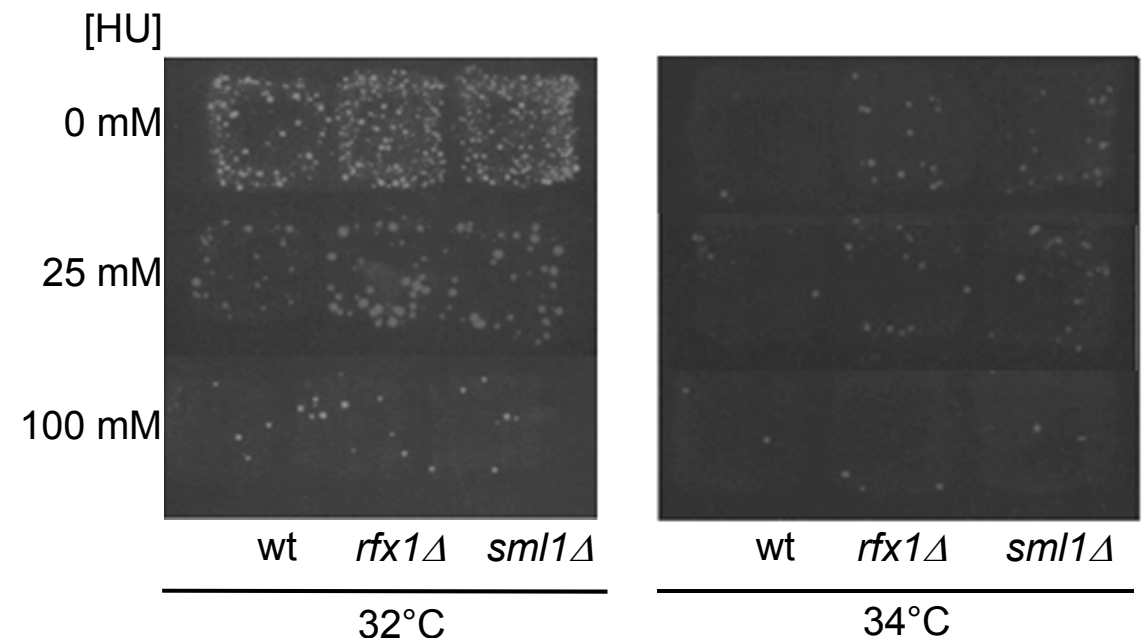

Figure 8 Effect of hydroxyurea on Ty1 mobility. (A) Yeast strains containing the galactose inducible Ty1 element on plasmid pGTy 1 his $3 \mathrm{AI}[\Delta 1]$ were induced at permissive temperature $\left(28^{\circ} \mathrm{C}\right)$ in the presence of varying concentrations of $\mathrm{HU}$ and quantitatively assayed for pGTy 1 mobility. $\mathrm{HU}$ treatment increases pGTy1 mobility in both wild type and sm/1 $\Delta$ strains, but not in the $\mathrm{rfx} 1 \Delta$ strain. (B) pGTy1 mobility patch assay at 32 and $34^{\circ} \mathrm{C}$. $\mathrm{HU}$ treatment drastically reduces pGTy 1 mobility in all strains at elevated temperatures. See Additional file 3 for numerical values.

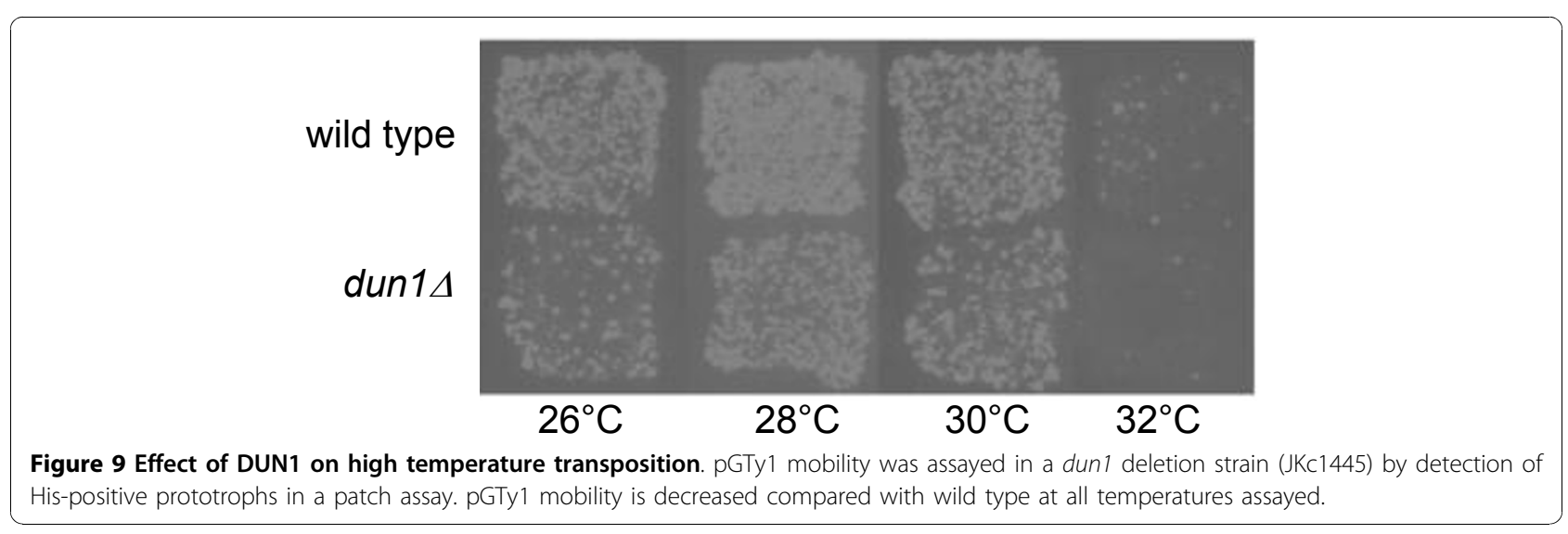


It is possible, however, that the modest increase in pGTy 1 mobility at 28 to $30^{\circ} \mathrm{C}$ in the mutant strains (Figure 2) could be mediated by more efficient processing of integrase (Figure 4). Deletion of the RTT101 gene (a cullin involved in replication through damaged DNA and pause sites) increased mobility of an endogenous Ty1 element, and increased levels of reverse transcriptase and integrase proteins [31]. It is important to note, however, that a plasmid encoded galactose-inducible Ty1 (pGTy1) element is required for protein studies and the frequency of mobility from a pGTy1 element is not increased in an rtt101د strain. Thus, it is thought that mobility of pGTy1 elements is limited at a late step, perhaps integration. Because we did not see an increase in cDNA levels in either deletion strain (discussed below), it is just as plausible that the modest increase in pGTy1 mobility at permissive temperatures in the deletion strains is the result of increased HR rather than an increase in processed integrase. Indeed, there was no difference in mobility between the wild type and mutant strains in a rad52 background at permissive temperature (Figure 5).

Our original working hypothesis was that the increase in pGTy1 mobility at high temperatures in $r f x 1 \Delta$ and $s m l 1 \Delta$ mutants was due to an increase in Ty1 cDNA resulting from increased dNTP substrates for reverse transcriptase. In fact, retroviral reverse transcriptase activity has been shown to vary with dNTP concentration. Oncoretroviruses and retroviruses show an increase of replication during cell division, when dNTP levels are elevated. Lentiviruses, such as HIV-1, are also capable of efficiently replicating in non-dividing cells (such as terminally differentiated cells) that have lower dNTP concentrations, because lentiviral reverse transcriptase has evolved to synthesize cDNA efficiently in these conditions [43]. We investigated the levels of Ty1 cDNA by Southern blot analysis using a restriction enzyme that would differentiate between Ty1 plasmid DNA, chromosomal Ty1 elements and their respective cDNAs (Figure 6A). We expected to see an increase in endogenous Ty1 cDNA and plasmid-derived cDNA in the deletion strains compared with the isogenic wild type strain. However, the analysis found no detectable difference in endogenous cDNA between strains as the temperature increased (Figure 6B). Thus, the increase in pGTy1 mobility at high temperature is probably not the result of increased Ty1 cDNA.

An interesting result of the Southern blot analysis was the marked reduction of endogenous cDNA in the $r f \times 1 \Delta$ strain grown at $26^{\circ} \mathrm{C}$ (Figure 6, table 1 ). This was particularly unexpected because RFX1 was previously reported by Scholes et al. as a marginal regulator of Ty1 cDNA-mediated mobility. That group found Ty1 cDNA to be modestly increased in the $r f x 1$ mutant, with the relative cDNA level measured at 1.7 compared with the parent strain [7]. However, there are several potentially important differences between their study and the present one. Scholes et al. measured mobility of an endogenous Ty1 element in a GRF167-derived strain. In this study, we measured pGTy1 mobility in a Hansenderived strain. We showed previously that pGTy1 mobility levels are considerably higher in GRF167-derived strains at $26^{\circ} \mathrm{C}$, perhaps due to more efficient production of Ty1 cDNA [3]. Additionally, Scholes et al. characterized an $r f x 1$ disruption allele, whereas in this study we characterized an $r f x 1$ deletion allele. We do not know why Ty1 cDNA levels dropped precipitously in the $r f x 1 \Delta$ strain at $26^{\circ} \mathrm{C}$, as Ty 1 protein production and processing are not defective at this temperature. If, as suggested by Curcio et al., the rate limiting step for pGTy1 elements is integration of cDNA, and Ty1 mobility is temperature sensitive, then perhaps much less Ty1 cDNA is required at lower temperatures to yield His-positive mobility events [31]. This possibility could potentially explain the faint pGTy1 cDNA signal (Figure 6B) and why we were unable to readily detect pGTy1 cDNA using a HIS3 probe (data not shown) unlike our previous work in GRF167-derived strains [8]. Additionally, a fortuitous Ty1 transcription termination signal in the HIS3 promoter (on the anti-sense strand relative to $\mathrm{Ty}$ ) causes premature termination in $\sim 50 \%$ of transcripts (Curcio J, personal communication). Strain differences in efficiency of transcript termination could also affect levels of pGTy1 cDNA. Given the variability in pGTy1 mobility and cDNA levels between different strain backgrounds, it is perhaps not so unexpected that the increase in pGTy 1 mobility in $r f x 1 \Delta$ and $s m l 1 \Delta$ mutants is strain specific. Other host gene mutations affecting Ty1 mobility that demonstrate strain specificity have been described [8].

At permissive temperatures, the primary Ty1 mobility mechanism is mediated by integrase, but at high temperature $\left(34^{\circ} \mathrm{C}\right)$, homologous recombination becomes the primary mechanism for genomic integration of Ty1 cDNA [8]. Deletion of $R A D 52$, which is required for homologous recombination, reduces or eliminates high temperature mobility in the mutant strains. Given that high temperature mobility is primarily mediated by HR, it seemed plausible that elevated dNTP levels in the mutant strains could mediate an increase in HR of Ty1 cDNA. We conducted a modified gap-repair assay in wild type, $r f \times 1 \Delta$ and sml1 $1 \Delta$ strains [8]. $\mathrm{n}$ the two deletion strains there was indeed an increase in efficiency of homologous recombination at $34^{\circ} \mathrm{C}$ compared with wild type. The phenotype was particularly notable in the $r f \times 1 \Delta$ strain at both 30 and $34^{\circ} \mathrm{C}$ (Figure 7). This result is consistent with the observation that the $r f \times 1 \Delta$ mediated increase in pGTy1 mobility at high temperature is exclusively dependent on HR, as introduction of 
the rad52 mutation eliminated the high temperature mobility phenotype (Figure 5). A recent study reported a novel function of RFX1 (CRT1) as a regulator of a Rad52-independent mitotic recombination pathway in yeast [44] rad52 $r f x 1$ double mutants were found to have a spontaneous recombination rate threefold higher than that of a rad52 single mutant. However, in contrast to this study, we found that deletion of $r f x 1$ alone did not affect recombination rates. The sml1 $\Delta$ rad52 strain retained pGTy1 mobility at high temperature $\left(34^{\circ} \mathrm{C}\right)$, suggesting that deletion of $s m l 1$ increases the efficiency of integrase-mediated transposition events at high temperature by an unknown mechanism. From these recombination experiments, we conclude that the increase in pGTy1 mobility at high temperature in the $r f \times 1 \Delta$ deletion strain is due to increased HR of available Ty1cDNA, mediated by an increase in cellular dNTP levels.

The shift from integrase-mediated to HR-mediated Ty1 mobility as temperature increases meshes nicely with deregulation of the RNR pathway in $r f \times 1 \Delta$ and sml1 $\Delta$ strains (Figure 1), because HR-mediated mobility would be expected to require more dNTPs than integrase-mediated mobility. Eukaryotic cells have two recombination pathways for dealing with free DNA ends, namely HR and non-homologous end-joining (NHEJ). The DNA synthesis step in homologous recombination is an energetic and resource-dependent process, requiring high stores of dNTPs to make the process more favourable [45]. Burkhalter et al. showed that the induction of RNR in mammalian cell lines increases the use of homologous recombination for chromosomal break repair [45]. Yeast cells innately show a strong preference for HR-mediated rather than NHEJ-mediated recombination [46]. When Ty1 integrase function is inhibited at high temperature, yeast cells resolve free Ty1 cDNA ends through genomic homologous recombination. We found that this HR process is more efficient with increased dNTPs.

\section{Integration of Ty1 mobility into the S-phase checkpoint pathway}

If the increase in pGTy1 mobility at high temperature $\left(34^{\circ} \mathrm{C}\right)$ in the $r f x 1 \Delta$ and $\operatorname{sml} 1 \Delta$ strains is the direct result of increased cellular dNTP levels, we would expect to see the high temperature phenotype abolished when cellular dNTP concentrations are lowered. Thus, we assayed pGTy1 mobility in the presence of HU, which inhibits RNR activity and reduces cellular dNTP levels $[42,47]$. Levels of dNTPs vary during the cell cycle, peaking shortly after the $G_{1} / S$ transition $[19,48]$, and treatment of yeast cells with HU reduces dNTP levels to $\sim 80 \%$ of $\mathrm{G}_{1}$ levels [42]. We found that the high temperature pGTy1 mobility phenotype was eliminated by
HU treatment (Figure 8B), and furthermore, mobility frequency was greatly reduced in all strains, even at the lowest levels of HU. Attempts to quantify pGTy1 mobility levels at high temperature $\left(34^{\circ} \mathrm{C}\right)$ in the presence of $\mathrm{HU}$ were unsuccessful because of the very low levels of mobility. However, pGTy1 mobility was quantified at permissive temperature, and found to be modestly induced by $\mathrm{HU}$ treatment (Figure 8A). This result is in agreement with previously published data, showing that HU treatment induced Ty1 mobility and cDNA levels through induction of the S-phase replication stress pathway (Figure 1) [31]. HU induction of Ty1 mobility is independent of $\mathrm{rad} 9$, and thus results from stalled replication forks resulting from inadequate dNTP levels [31].

In the presence of $\mathrm{HU}$, deletion of the RNR regulators may increase basal dNTP levels to an adequate level to prevent replication fork pausing and subsequent induction of Ty1 mobility through the S-phase replication stress pathway. We found that although pGTy1 mobility was induced in both the wild type and $\operatorname{sml} 1 \Delta$ strains, mobility was not induced in the $r f x 1 \Delta$ strain (Figure 8). In a recent study of the induction of the DNA damage checkpoint, Tang et al. carefully quantified levels of all

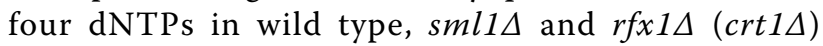
strains during logarithmic growth [16]. The levels of dNTPs in the $r f x 1 \Delta$ strain were shown to be modestly but significantly higher than those in an $\operatorname{sml1\Delta }$ strain. Given the tight regulation of cellular dNTP levels, this small difference may be enough to trigger the S-phase replication stress pathway, and subsequently pGTy1 mobility, in the $\operatorname{sml} 1 \Delta$ strain but not the $r f x 1 \Delta$ strain. Activation of the S-phase checkpoint pathways has been directly assayed by measuring the induction of phosphorylated Rad53 protein; however, our laboratory has been unsuccessful in detection of phosphorylated Rad53 $[16,49,50]$.

To further investigate the link of the high temperature mobility phenotype to the S-phase checkpoint pathway, we investigated the effects of manipulating the expression of the upstream kinase Dun1. Activation of Dun1 kinase activity inactivates both Rfx1 and Sml1 (Figure 1). Thus, overexpression of Dun1 might increase dNTP levels and subsequently pGTy1 mobility in wild type strains; however, we found was no effect. Because the plasmid contains the DUN1 gene promoter, it is possible that DUN1 expression levels from the plasmid are kept at basal levels. Conversely, deletion of $d u n 1$ would result in more actively repressive forms of $\mathrm{Rfx} 1$ and Sml1, and in fact, the levels of cellular dNTPs were found to be reduced in a dun1s strain [17]. We found that deletion of Dun1 provided a consistent decrease in pGTy1 mobility from 26 to $32^{\circ} \mathrm{C}$ (Figure 9). This decrease in mobility in the dun1 strain confirms that Ty1 mobility, both integration and HR mediated, is linked to S-phase checkpoint regulation 
[31]. Overall, these results support our conclusion that pGTy1 mobility is intimately linked to dNTP levels in the cell and integrated with S-phase checkpoint pathways through regulation of dNTP levels.

\section{Conclusions}

In this study, we found that an increase in dNTP levels through deletion of the RNR regulators $\mathrm{Rfx} 1$ and $\mathrm{Sml} 1$ stimulated pGTy1 mobility at high temperature $\left(34^{\circ} \mathrm{C}\right)$. This increase in pGTy1 mobility at high temperature is not due to an increase of Ty1 cDNA, but rather is mediated by an increase in the efficiency of homologous recombination of existing Ty1 cDNA. These results confirm that at high temperature, when Ty1 protein processing is inhibited, Ty1 mobility is mediated by homologous recombination. Levels of cellular dNTPs, as regulated by components of the $\mathrm{S}$-phase checkpoint pathway, are a limiting factor in HR-mediated Ty1 mobility.

\section{Methods}

\section{Yeast strains and plasmids}

The yeast strains and plasmids used in this study are given in Table 2. Yeast strains were maintained according to standard methods and media prepared as previously described [51]. Plasmid pGTy1H3mhis3AI, used for the initial genetic screen and quantitative assays, contains a galactose-inducible Ty1 element on a URA3, $2-\mu \mathrm{m}$ plasmid [35]. Subsequent mobility assays used plasmid pGTy1his3AI[ $\Delta 1$ ] (kind gift of D Garfinkel) [7]. In this plasmid construct, the AI insertion in the plasmid his 3 marker is located within the corresponding sequence deleted in the his $3 \Delta 1$ marker in strain Hansen BY4741; this eliminates the formation of background His-positive events by homologous recombination of the genomic his $3 \Delta 1$ marker with plasmid sequences. The DUN1 LEU2, 2-micron plasmid (pJK679) was made by TOPO TA cloning of a 1948 bp PCR fragment containing the DUN1 gene into plasmid pCR2.1-TOPO (Invitrogen, Carlsbad, CA, USA) using the primers JK323 and JK324 (Table 3). The XhoI/SpeI fragment of this construct was then cloned into the same sites of plasmid pRS425.

\section{Deletion pool transformation, screening and gene identification}

A MATa pool of the S. cerevisiae deletion library, containing $~ 5200$ unique deleted ORFs, was transformed with plasmid pGTy1H3mhis3AI [35]. Transformants $(>25,000)$ were selected on synthetic complete medium lacking uracil (SC-Ura) for 3 days at $30^{\circ} \mathrm{C}$. Colonies were replica plated to galactose medium lacking uracil prewarmed to $34^{\circ} \mathrm{C}$, and incubated for 48 hours. Cells were then replica plated to $\mathrm{SC}$-His prewarmed to $34^{\circ} \mathrm{C}$. Colonies showing greater growth than the wild type on $\mathrm{SC}$-His were patched from the SC-Ura transformation plates to fresh medium, and assayed to confirm the high temperature mobility phenotype. The deleted ORF was identified from nine independent clones, each showing high temperature pGTy1 mobility. Genomic DNA was isolated from positive clones and used in a PCR reaction employing the common primers U1 and D1 (Table 3). Three clones did not amplify a product using the U1 and D1 primers. For these clones, primers complementary to the kanmx deletion gene and heading towards the downtag (JK196) or the uptag (JK197) sequences were paired with primers D1 or U1 respectively. A product was obtained using the U1/uptag primer pair. The resulting PCR products were purified (PCR Purification Kit; Qiagen, Valencia, CA, USA) and sequenced using the uptag primer. The resulting sequence was compared with the deletion uptag and downtag sequences to identify the disrupted ORF.

\section{Ty1 mobility assays}

Patch assays and quantitative assays were performed as previously described [8]. For the $\mathrm{HU}$ assays, patches were grown on SC-Ura plates for 24 to 36 hours at $30^{\circ}$ $\mathrm{C}$ and then replica plated to SC-Ura with $2 \%$ galactose and varying concentrations of $\mathrm{HU}$ (0 to $100 \mathrm{mmol} / \mathrm{l}$ ). Plates were equilibrated to the induction temperature before replica plating. After 24 hours, patches were replica plated to $\mathrm{SC}$-His at $30^{\circ} \mathrm{C}$. Papillae are usually visible within 24-36 hours.

For quantification, strains were grown as $12 \times 12 \mathrm{~mm}$ patches on SC-Ura plates at $30^{\circ} \mathrm{C}$ for 24 to 36 hours. The patches were then transferred into $15 \mathrm{~mL}$ of SC-Ura plus $2 \%$ galactose medium with varying concentrations of $\mathrm{HU}$ with an optical density at $600 \mathrm{~nm}\left(\mathrm{OD}_{600}\right)$ of approximately 0.4 . The medium was pre-incubated to the induction temperature. After 2 days of growth, the $\mathrm{OD}_{600}$ was approximately 1.2. A counting chamber (Number 100 Hy-Lite Chamber; Hausser Scientific, Horsham, PA, USA) was used to count cells, giving a volume $\sim 0.5-1 \times$ $10^{8}$ cells $/ \mathrm{ml}$. Cells were then diluted and plated onto SCHis to assess frequency of pGTy1 mobility and to yeastextract peptone dextrose (YPD) agar to determine the number of viable cells. For assessing the frequency of pGTy1 mobility at $28^{\circ} \mathrm{C}, 100 \mu \mathrm{l}$ of cells at $\sim 1000$ cells $/ \mu \mathrm{l}$ were plated onto SC-His. At $34^{\circ} \mathrm{C}$ mobility is much lower, so that $0.5-1 \mathrm{ml}$ of cells were plated onto SC-His. For assessing viability, cells were diluted to $\sim 1 \mathrm{cell} / \mu \mathrm{l}$ and $100 \mu \mathrm{l}$ was plated to YPD. Frequency of pGTy1 mobility was calculated as the number of His-positive papillae/ total cells plated. All strains were patched, inoculated and plated in triplicate for each temperature and $\mathrm{HU}$ 
Table 2 Yeast strains used in this study

\begin{tabular}{|c|c|c|c|c|}
\hline $\begin{array}{l}\text { JKc } \\
\text { number }\end{array}$ & Parent strain & Genotype & Plasmid name & Source \\
\hline JKc1046 & $\begin{array}{l}\text { Hansen } \\
\text { BY4741 }\end{array}$ & 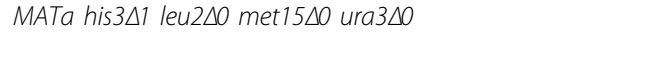 & none & Invitrogen \\
\hline JKc1356 & $\begin{array}{l}\text { Hansen } \\
\text { BY4741 }\end{array}$ & 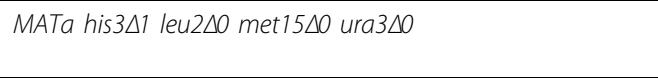 & pGTy1his3AI[A1] (URA3, $2 \mu)$ & Invitrogen \\
\hline $\mathrm{JKC1357}$ & $\begin{array}{l}\text { Hansen } \\
\text { BY4741 }\end{array}$ & 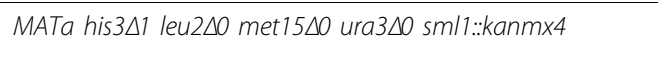 & pGTy1his3AI[D1] $(U R A 3,2 \mu)$ & Invitrogen \\
\hline $\mathrm{JKc1358}$ & $\begin{array}{l}\text { Hansen } \\
\text { BY4741 }\end{array}$ & 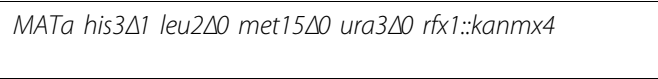 & pGTy1his3AI[A1] (URA3, $2 \mu)$ & Invitrogen \\
\hline JKc1359 & $\begin{array}{l}\text { Hansen } \\
\text { BY4741 }\end{array}$ & 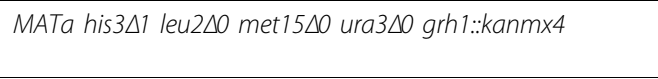 & pGTy1his3AI[L1] (URA3, $2 \mu)$ & Invitrogen \\
\hline JKc1360 & $\begin{array}{l}\text { Hansen } \\
\text { BY4741 }\end{array}$ & 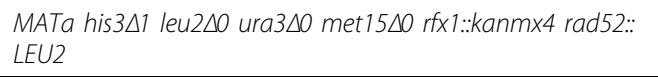 & pGTy1his3AI[L1] (URA3, $2 \mu)$ & This study \\
\hline JKc1361 & $\begin{array}{l}\text { Hansen } \\
\text { BY4741 }\end{array}$ & 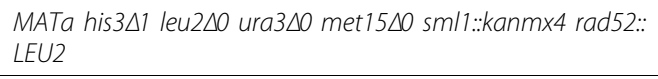 & pGTy1his3AI[L1] (URA3, $2 \mu)$ & This study \\
\hline JKc1363 & $\begin{array}{l}\text { Hansen } \\
\text { BY4741 }\end{array}$ & 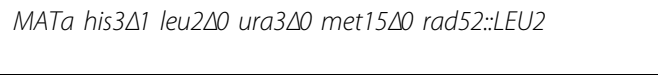 & pGTy1his3AI[L1] (URA3, $2 \mu)$ & This study \\
\hline JKC1424 & $\begin{array}{l}\text { Hansen } \\
\text { BY4741 }\end{array}$ & 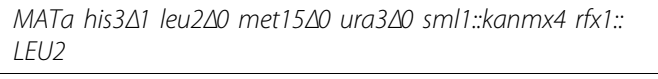 & pGTy1his3AI[L1] (URA3, $2 \mu)$ & This study \\
\hline $\mathrm{JKc} 1425$ & $\begin{array}{l}\text { Hansen } \\
\text { BY4741 }\end{array}$ & 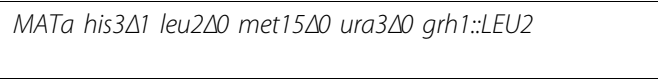 & pGTy1his3AI[L1] (URA3, $2 \mu)$ & This study \\
\hline JKc1426 & $\begin{array}{l}\text { Hansen } \\
\text { BY4741 }\end{array}$ & 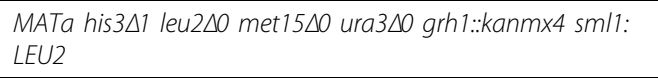 & pGTy1his3AI[L1] (URA3, $2 \mu)$ & This study \\
\hline JKc1427 & $\begin{array}{l}\text { Hansen } \\
\text { BY4741 }\end{array}$ & 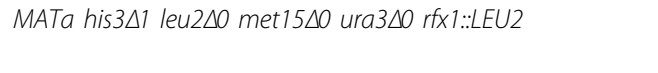 & pGTy1his3AI[L1] $(U R A 3,2 \mu)$ & This study \\
\hline JKc1428 & $\begin{array}{l}\text { Hansen } \\
\text { BY4741 }\end{array}$ & 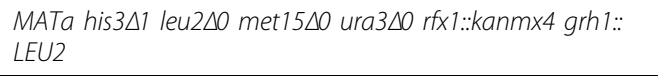 & pGTy1his3AI[L1] (URA3, $2 \mu)$ & This study \\
\hline JKc1429 & $\begin{array}{l}\text { Hansen } \\
\text { BY4741 }\end{array}$ & 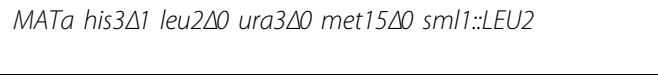 & pGTy1his3AI[L1] (URA3, $2 \mu)$ & This study \\
\hline $\mathrm{JKC1445}$ & $\begin{array}{l}\text { Hansen } \\
\text { BY4741 }\end{array}$ & 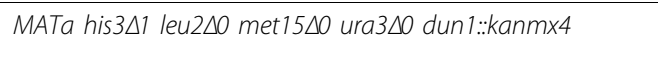 & pGTy1his3AI[L1] (URA3, $2 \mu)$ & Invitrogen \\
\hline JKc1499 & $\begin{array}{l}\text { Hansen } \\
\text { BY4741 }\end{array}$ & 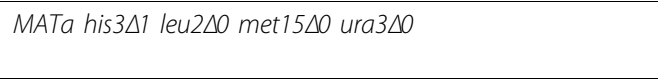 & $\begin{array}{l}\text { pGTy1his3AI[D1] (URA3, } 2 \mu \text { pJK679 (DUN1 } \\
\text { LEU2 } 2 \mu \text { ) }\end{array}$ & This study \\
\hline JKc1532 & $\begin{array}{l}\text { Hansen } \\
\text { BY4741 }\end{array}$ & 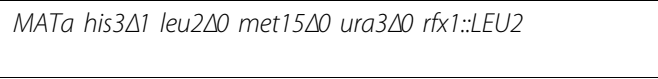 & None & This study \\
\hline JKc1533 & $\begin{array}{l}\text { Hansen } \\
\text { BY4741 }\end{array}$ & 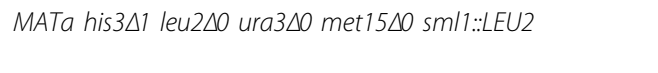 & None & This study \\
\hline
\end{tabular}

concentration. The average mobility and standard deviation was calculated for each point.

\section{Rad52 strain construction}

Plasmid pSM20, containing the rad52::LEU2 allele, was digested with $B a m$ HI. Digestion was confirmed by gel electrophoresis, yielding two bands of $5 \mathrm{kbp}$ and $4.6 \mathrm{kbp}$. The remaining digest was transformed into yeast [52], and cells were plated to SC-Leu medium to select for integration of the disrupted rad52 allele. Isolated transformants were confirmed by ultraviolet-induced growth sensitivity compared with the isogenic $R A D 52$ parent.

\section{Deletion constructs}

PCR products for targeted deletions of ORFs with kanmx or LEU2 was obtained by using pRS400 or pRS425, respectively, as target DNA as described previously [53]. For RFX1 deletion constructs, the forward primer JK198 and the reverse primer JK199 were used; or SML1 deletion constructs, the forward primer JK293 and the reverse primer JK294 were used; and for GRH1 deletion constructs, the forward primer JK295 and reverse primer JK296 were used. PCR conditions were as described previously, using a thermostable polymerase (PfuTurbo; Stratagene, a division of Agilent, Santa Clara, CA, USA). The resulting PCR product was transformed into competent yeast strains by lithium acetate transformation [52].

\section{Immunoblotting}

Cell growth and protein isolation were performed as described previously [8]. Whole cell extracts were mixed with an equal volume of $2 \times$ sample loading buffer $(20 \% \mathrm{v} /$ 
Table 3 Primers used in the experiments

\begin{tabular}{|c|c|}
\hline Primer name & Sequence $\mathbf{5}^{\prime} \rightarrow \mathbf{3}^{\prime}$ \\
\hline U1 & GATGTCCACGAGGTCTCT \\
\hline$\overline{\mathrm{D} 1}$ & CGGTGTCGGTCTCGTAG \\
\hline JK181 & TGCGATCTCTTTAAAGGGTG \\
\hline JK182 & TTGGTGGAGGGAACATCGTT \\
\hline JK196 & CAGATGCGAAGTTAAGTG \\
\hline JK197 & GACAGTCACATCATGCCC \\
\hline JK198 & GGCGATTTGGGAAAAAGTTGAAAAAAAAAATAGCAGTAAAGATTGTACTGAGAGTGCAC \\
\hline JK199 & GTTATATTCTITITIAAATATCCCCATATACTAATGATAGCTGTGCGGTATTTCACACCG \\
\hline JK293 & CTTATCTGCTCCTITGTGATCTTACGGTCTCACTAACCTCAGATTGTACTGAGAGTGCAC \\
\hline JK294 & TAGTAGGACGAGAGTCCCTGAAAAGAAGGGTATCTAAGAGCTGTGCGGTATTTCACACCG \\
\hline JK295 & CACAGCGTGCGAAACTAGGGAAGTAAAAAGGTATAGGAAGAGATTGTACTGAGAGTGCAC \\
\hline JK296 & CCAACTATGCTTAACGTGTTITGAAGGGAAAGCAAGCTTACTGTGCGGTATTTCACACCG \\
\hline JK323 & AAAAACGATAGGGTGGCACA \\
\hline JK324 & GAAGCCCCTGAATACCATAAA \\
\hline JK349 & AGATGCAATACGACACCAAGA \\
\hline$J K 350$ & CGGAAGAGGTTTTGTCATCA \\
\hline
\end{tabular}

v glycerol, $0.125 \mathrm{M}$ Tris- $\mathrm{HCl}, \mathrm{pH} 6.8,5 \% \mathrm{w} / \mathrm{v} \mathrm{SDS}, 10 \% \mathrm{v} /$ v $14 \mathrm{~mol} / \mathrm{l} \beta$-mercaptoethanol, $0.2 \% \mathrm{w} / \mathrm{v}$ bromophenol blue) and boiled for 3 minutes before loading onto a $10 \%$ (Gag blots) or 7.5\% (Pol blots) SDS gel. Gels were transferred to nitrocellulose (Gag blots) or PVDF (Pol blots) membranes in Tris-glycine buffer containing 10\% methanol at $24 \mathrm{~V}$ for 1 hour. Membranes were blocked in buffer I (15 mM Tris, pH8, $150 \mathrm{mmol} / \mathrm{l} \mathrm{NaCl}, 0.25 \% \mathrm{w} / \mathrm{v}$ gelatine (G7041, Sigma Chemical Co, St Louis, MO, USA) and $0.25 \% \mathrm{v} / \mathrm{v}$ Tween-20) overnight at $4^{\circ} \mathrm{C}$. Membranes were then probed with antibody for 1 hour at room temperature in Buffer II (15 mmol/l Tris, pH8, $150 \mathrm{mmol} / \mathrm{l} \mathrm{NaCl}$, $0.25 \% \mathrm{w} / \mathrm{v}$ gelatine, $0.25 \% \mathrm{v} / \mathrm{v}$ Tween -20 and $7.5 \mathrm{mmol} / \mathrm{l}$ EDTA) and washed twice for 5 minutes in fresh Buffer II. The appropriate secondary antibody was diluted in Buffer II and added to the membrane, which was then washed four times for 5 minutes each in Buffer II, followed by Amersham ECL (nitrocellulose) or Amersham ECL-Plus (PVDF) reagent (GEHealthcare Life Sciences, Piscataway, NJ USA) and exposed on a image station (2000R; Eastman Kodak Co., Rochester, NY, USA). Anti-Gag (anti-VLP polyclonal serum R2-F) and anti-integrase (8B-11 monoclonal antibody) were as described previously [54,55]. Rabbit polyclonal antiserum to a synthetic peptide (CTKYTPDKKIVSNAS) of the yeast protein Gadph $(T D H 1)$,was used as a loading control.

\section{cDNA Southern analysis}

For induction of Ty1 cDNA, cells were inoculated into $100 \mathrm{ml}$ VLP medium plus raffinose at a starting $\mathrm{OD}_{600}$ of $\sim 0.15$, and grown at $30^{\circ} \mathrm{C}$ for 4 hours. Galactose was added to a final concentration of $2 \%$, and cells were grown for 12 hours at the induction temperature. Genomic DNA was isolated as described previously [56]. Aliquots $(10 \mu \mathrm{l} ; \sim 50-100 \mu \mathrm{g})$ of DNA were digested with $5 \mathrm{U}$ SphI for 20 hours in a $50 \mu \mathrm{l}$ reaction containing $1 \mu \mathrm{l}$ RNase $(10 \mathrm{mg} / \mathrm{ml})$. Samples were electrophoretically separated $(0.75 \%$ agarose gel) and transferred to a hybridization transfer membrane (GeneScreen; Perkin Elmer, Fremont, CA, USA) and hybridized to a 887 bp probe. The probe was generated using pGTy $1 \mathrm{H} 3 \mathrm{~m} h i s 3 \mathrm{AI} \Delta 1$ as template DNA in a PCR reaction with 25 cycles of denaturing at $95^{\circ} \mathrm{C}$ for 1 minute, annealing at $59^{\circ} \mathrm{C}$ for 1 minute and extension at $72^{\circ} \mathrm{C}$ extension for 1 minute) with primers JK349 and JK35 (Table 3). The PCR product $(5 \mu \mathrm{l})$ was labelled (NEBlot Kit; New England Biolabs, Ipswich, MA, USA), purified (Nucleotide Removal Kit; Qiagen) and hybridized to genomic DNA as described previously [8]. The location of expected bands was determined from a standard curve generated using the molecular weight standards. The membrane was washed twice for 5 minutes in $2 \times$ saline sodium citrate buffer at room temperature and exposed overnight at $-80^{\circ} \mathrm{C}$ to film with an enhancing screen. For quantifying the signal, the image file of the scanned film was imported into image analysis software (1D; Kodak). The image lane and band location functions, and the net intensity, which is the sum of the background-subtracted pixel values in the band rectangle, were used to determine the ratios of the relative amounts of cDNA in each band.

\section{Recombination assays}

Strains JKc1046, JKc1532 and JKc1533 were inoculated into YPD at 30 or $34^{\circ} \mathrm{C}$ at an absorbance at $600 \mathrm{~nm}$ 
$\left(\mathrm{A}_{600}\right)$ of $\sim 0.05$ and grown to an $\mathrm{A}_{600}$ of $\sim 0.7$. Cells were washed twice in water and frozen at $-80^{\circ} \mathrm{C}$ in $0.1 \mathrm{M}$ lithium acetate/Tris EDTA buffer with $15 \%$ glycerol. The HIS3 linear DNA fragment for transformation was made using plasmid pJK592 $(0.2 \mathrm{ng} / \mu \mathrm{L})$ as template DNA with primers JK181 and JK182 (Table 3), generating a $590 \mathrm{bp}$ product. Cell aliquots $(100 \mu \mathrm{l})$ were thawed and transformed with $7.8 \mu \mathrm{g}$ of PCR product as described previously [52], except that for $34^{\circ} \mathrm{C}$ transformation reactions, reagents were preheated to $34^{\circ} \mathrm{C}$ and all incubation steps were carried out at $34^{\circ} \mathrm{C}$. Plasmid pJK592 was transformed $(0.7 \mu \mathrm{g}$ into JKc1532; $0.07 \mu \mathrm{g}$ into JKc1046 and JKc1533) to assess efficiency of transformation. His-positive prototrophs were selected by plating onto $\mathrm{SC}$-His medium at 30 or $34^{\circ} \mathrm{C}$. Recombination efficiency was determined from transformation of the PCR product and was calculated as number of colony-forming units (cfu) per total number of cells in the transformation reaction as determined by direct cell counts in a thawed aliquot. The recombination efficiency was normalized to wild type, and then multiplied by a transformation efficiency factor, the inverse of the average number of His-positive cfu/total cell number normalized to wild type for transformation of plasmid DNA. Each strain was transformed in triplicate at both temperatures. Results are reported as the means and standard deviation for each set.

\section{Additional material}

Additional file 1: Figure 2 data. Numerical values for data shown in Figure 2. A table of the average (+/- standard deviation) values of Hispositive prototroph formation for each of the points graphed in Figure 2.

Additional file 2: Figure $\mathbf{5}$ data. Numerical values for data shown in Figure 5. A table of the average (+/- standard deviation) values of Hispositive prototroph formation for each of the points graphed in Figure 5.

Additional file 3: Figure 8A data. Numerical values for data shown in Figure 8A. A table of the average (+/- standard deviation) values of Hispositive prototroph formation for each of the points graphed in Figure $8 \mathrm{~A}$.

\footnotetext{
Acknowledgements

We thank the Juniata College Bl307: Molecular Techniques class of spring semester 2004, who conducted the screen of the yeast deletion library., and Mary Heaton, who identified the mutant genes as part of her senior thesis at Juniata College (spring semester 2005). We also thank to Leigh Zimmerman and Justin Neidig for technical help with quantitative assays and protein analysis. Funding for this study was provided in part by $\mathrm{NIH}$ Grant R15GM074658-01 to JBK and support from the William J. von Liebig Foundation.
}

\section{Author details}

'Department of Biology, Juniata College, Huntingdon, PA, USA. ${ }^{2}$ Department of Molecular Medicine, Cornell University, Ithaca, NY 14853-6401, USA. ${ }^{3}$ University of Kentucky College of Medicine, Lexington, KY 40506, USA.

\section{Authors' contributions}

JO performed the Southern blot analyses, HU assays, DUN1 cloning and deletion construction and assays, and drafted the introduction, parts of the results and the conclusions. MG created the deletion strains and rad52 constructs, and performed the mobility assays and homologous recombination assays, and also attempted to develop an in vitro assay to measure reverse transcriptase activity at varying dNTP concentrations (data not shown). JK supervised the research, helped with the quantitative assays, performed the protein analysis and finalized the manuscript.

\section{Authors' information}

MG participated in this study as an undergraduate student at Juniata College. receiving a BS in May 2009, and is currently enrolled in the graduate program at University of Kentucky. JO completed work on the project as an undergraduate at Juniata College, and it formed the basis of his undergraduate honors thesis. He received his BS in May 2010 and is currently enrolled in the graduate program at Cornell University. JK is the David K. Goodman '74 Endowed Chair in Biology at Juniata College.

\section{Competing interests}

The authors declare that they have no competing interests.

Received: 9 August 2010 Accepted: 22 November 2010 Published: 22 November 2010

\section{References}

1. Havecker ER, Gao X, Voytas DF: The diversity of LTR retrotransposons. Genome Biol 2004, 5:225.

2. Curcio MJ, Hedge AM, Boeke JD, Garfinkel DJ: Ty RNA levels determine the spectrum of retrotransposition events that activate gene expression in Saccharomyces cerevisiae. Mol Gen Genet 1990, 220:213-221.

3. Lawler JF Jr, Haeusser DP, Dull A, Boeke JD, Keeney JB: Ty1 defect in proteolysis at high temperature. J Virol 2002, 76:4233-4240.

4. Curcio MJ, Garfinkel DJ: Regulation of retrotransposition in Saccharomyces cerevisiae. Molecular microbiology 1991, 5:1823-1829.

5. Griffith JL, Coleman LE, Raymond AS, Goodson SG, Pittard WS, Tsui C, Devine SE: Functional genomics reveals relationships between the retrovirus-like Ty1 element and its host Saccharomyces cerevisiae. Genetics 2003, 164:867-879.

6. Irwin B, Aye M, Baldi P, Beliakova-Bethell N, Cheng H, Dou Y, Liou W, Sandmeyer S: Retroviruses and yeast retrotransposons use overlapping sets of host genes. Genome research 2005, 15:641-654.

7. Scholes DT, Banerjee M, Bowen B, Curcio MJ: Multiple regulators of Ty1 transposition in Saccharomyces cerevisiae have conserved roles in genome maintenance. Genetics 2001, 159:1449-1465.

8. Radford SJ, Boyle M, Sheely CJ, Graham J, Haeusser DP, Keeney JB: Increase in Ty1 cDNA recombination in yeast sir4 mutant strains at high temperature. Genetics 2004, 168:89-101.

9. Beauregard A, Curcio MJ, Belfort M: The take and give between retrotransposable elements and their hosts. Annual review of genetics 2008, 42:587-617.

10. Maxwell PH, Curcio MJ: Host factors that control long terminal repeat retrotransposons in Saccharomyces cerevisiae: implications for regulation of mammalian retroviruses. Eukaryot Cell 2007, 6:1069-1080.

11. Huang $M$, Zhou Z, Elledge SJ: The DNA replication and damage checkpoint pathways induce transcription by inhibition of the Crt1 repressor. Cell 1998, 94:595-605.

12. Zhang Z, Reese JC: Molecular genetic analysis of the yeast repressor $\mathrm{Rfx} 1 / \mathrm{Crt1}$ reveals a novel two-step regulatory mechanism. Mol Cell Biol 2005, 25:7399-7411.

13. Zaim J, Speina E, Kierzek AM: Identification of new genes regulated by the Crt1 transcription factor, an effector of the DNA damage checkpoint pathway in Saccharomyces cerevisiae. J Biol Chem 2005, 280:28-37.

14. Andreson BL, Gupta A, Georgieva BP, Rothstein R: The ribonucleotide reductase inhibitor, $\mathrm{Sml}$, is sequentially phosphorylated, ubiquitylated and degraded in response to DNA damage. Nucl Acids Res gkq552.

15. Zhang Z, Yang $K$, Chen CC, Feser J, Huang M: Role of the $C$ terminus of the ribonucleotide reductase large subunit in enzyme regeneration and its inhibition by Sml1. Proc Natl Acad Sci USA 2007, 104:2217-2222.

16. Tang H-MV, Siu KL, Wong CM, Jin DY: Loss of yeast peroxiredoxin Tsa1p induces genome instability through activation of the DNA damage checkpoint and elevation of dNTP levels. PLOS Genet 2009, 5:e1000697. 
17. Fasullo M, Tsaponina O, Sun M, Chabes A: Elevated dNTP levels suppress hyper-recombination in Saccharomyces cerevisiae S-phase checkpoint mutants. Nucleic Acids Res 2010, 38:1195-1203.

18. Zhao X, Muller EG, Rothstein R: A suppressor of two essential checkpoint genes identifies a novel protein that negatively affects dNTP pools. Mol Cell 1998, 2:329-340.

19. Chabes A, Georgieva B, Domkin V, Zhao X, Rothstein R, Thelander L: Survival of DNA damage in yeast directly depends on increased dNTP levels allowed by relaxed feedback inhibition of ribonucleotide reductase. Cell 2003, 112:391-401.

20. Zhao X, Chabes A, Domkin V, Thelander $L$, Rothstein $R$ : The ribonucleotide reductase inhibitor Sml1 is a new target of the Mec1/Rad53 kinase cascade during growth and in response to DNA damage. Embo J 2001, 20:3544-3553

21. Kondo T, Wakayama T, Naiki T, Matsumoto K, Sugimoto K: Recruitment of Mec1 and Ddc1 checkpoint proteins to double-strand breaks through distinct mechanisms. Science 2001, 294:867-870.

22. Melo JA, Cohen J, Toczyski DP: Two checkpoint complexes are independently recruited to sites of DNA damage in vivo. Genes Dev 2001, 15:2809-2821.

23. Bellaoui M, Chang M, Ou J, Xu H, Boone C, Brown GW: Elg1 forms an alternative RFC complex important for DNA replication and genome integrity. EMBO J 2003, 22:4304-4313.

24. Ben-Aroya S, Koren A, Liefshitz B, Steinlauf R, Kupiec M: ELG1, a yeast gene required for genome stability, forms a complex related to replication factor C. Proc Natl Acad Sci USA 2003, 100:9906-9911.

25. Kanellis P, Agyei R, Durocher D: Elg1 forms an alternative PCNAinteracting RFC complex required to maintain genome stability. Curr Biol 2003, 13:1583-1595.

26. Sanchez Y, Bachant J, Wang H, Hu F, Liu D, Tetzlaff M, Elledge SJ: Control of the DNA damage checkpoint by chk1 and rad53 protein kinases through distinct mechanisms. Science 1999, 286:1166-1171.

27. Sun Z, Hsiao J, Fay DS, Stern DF: Rad53 FHA domain associated with phosphorylated Rad9 in the DNA damage checkpoint. Science 1998 281:272-274

28. Zhao X, Rothstein R: The Dun1 checkpoint kinase phosphorylates and regulates the ribonucleotide reductase inhibitor Sml1. Proc Natl Acad Sci USA 2002, 99:3746-3751.

29. Zhou Z, Elledge SJ: DUN1 encodes a protein kinase that controls the DNA damage response in yeast. Cell 1993, 75:1119-1127.

30. Segurado M, Tercero JA: The S-phase checkpoint: targeting the replication fork. Biol Cell 2009, 101:617-627.

31. Curcio MJ, Kenny AE, Moore S, Garfinkel DJ, Weintraub M, Gamache ER, Scholes DT: S-Phase checkpoint pathways stimulate the mobility of the retrovirus-like transposon Ty1. Mol Cell Biol 2007, 27:8874-8885.

32. Scholes DT, Kenny AE, Gamache ER, Mou Z, Curcio MJ: Activation of a LTRretrotransposon by telomere erosion. Proc Natl Acad Sci USA 2003, 100:15736-15741.

33. Teng SC, Kim B, Gabriel A: Retrotransposon reverse-transcriptasemediated repair of chromosomal breaks. Nature 1996, 383:641-644.

34. Winzeler EA, Shoemaker DD, Astromoff A, Liang H, Anderson K, Andre B, Bangham R, Benito R, Boeke JD, Bussey $H$, et al: Functional characterization of the $\mathrm{S}$. cerevisiae genome by gene deletion and parallel analysis. Science 1999, 285:901-906.

35. Curcio MJ, Garfinkel DJ: Single-step selection for Ty1 element retrotransposition. Proc Natl Acad Sci USA 1991, 88:936-940.

36. Levi SK, Bhattacharyya D, Strack RL, II JRA, Glick BS: The yeast GRASP Grh colocalizes with COPII and Is dispensable for organizing the secretory pathway. Traffic 2010, 11:1168-79.

37. Lehner KR, Stone MM, Farber RA, Petes TD: ninety-six haploid yeast strains with individual disruptions of open reading frames between YOR097C and YOR192C, constructed for the Saccharomyces Genome Deletion Project, have an additional mutation in the mismatch repair gene MSH3. Genetics 2007, 177:1951-1953.

38. Chabes A, Stillman B: Constitutively high dNTP concentration inhibits cell cycle progression and the DNA damage checkpoint in yeast Saccharomyces cerevisiae. Proc Natl Acad Sci USA 2007, 104:1183-1188,

39. Merkulov GV, Lawler JF Jr, Eby Y, Boeke JD: Ty1 proteolytic cleavage sites are required for transposition: all sites are not created equal. J Virol 2001, 75:638-644.
40. Sharon G, Burkett TJ, Garfinkel DJ: Efficient homologous recombination of Ty1 element cDNA when integration is blocked. Mol Cell Biol 1994, 14:6540-6551.

41. Aguilera J, Randez-Gil F, Prieto JA: Cold response in Saccharomyces cerevisiae: new functions for old mechanisms. FEMS microbiology reviews 2007, 31:327-341.

42. Koc A, Wheeler LJ, Mathews CK, Merrill GF: Hydroxyurea arrests dna replication by a mechanism that preserves basal dNTP pools. J Biol Chem 2004, 279:223-230

43. Diamond $T L$, Roshal M, Jamburuthugoda VK, Reynolds HM, Merriam AR, Lee KY, Balakrishnan M, Bambara RA, Planelles V, Dewhurst S, Kim B: Macrophage tropism of HIV-1 depends on efficient cellular dNTP utilization by reverse transcriptase. J Biol Chem 2004, 279:51545-51553.

44. Coic E, Feldman T, Landman AS, Haber JE: Mechanisms of Rad52independent spontaneous and UV-induced mitotic recombination in Saccharomyces cerevisiae. Genetics 2008, 179:199-211.

45. Burkhalter MD, Roberts SA, Havener JM, Ramsden DA: Activity of ribonucleotide reductase helps determine how cells repair DNA double strand breaks. DNA Repair 2009, 8:1258-1263.

46. Lee SE, Paques F, Sylvan J, Haber JE: Role of yeast SIR genes and mating type in directing DNA double-strand breaks to homologous and nonhomologous repair paths. Curr Biol 1999, 9:767-770.

47. Santocanale C, Diffley JF: A Mec1- and Rad53-dependent checkpoint controls late-firing origins of DNA replication. Nature 1998, 395:615-618.

48. Koc A, Wheeler LJ, Mathews CK, Merrill GF: Replication-independent MCB gene induction and deoxyribonucleotide accumulation at G1/S in Saccharomyces cerevisiae. J Biol Chem 2003, 278:9345-9352.

49. Sun Z, Fay DS, Marini F, Foiani M, Stern DF: Spk1/Rad53 is regulated by Mec1-dependent protein phosphorylation in DNA replication and damage checkpoint pathways. Genes Dev 1996, 10:395-406.

50. Sanchez Y, Desany BA, Jones WJ, Liu Q, Wang B, Elledge SJ: Regulation of RAD53 by the ATM-like kinases MEC1 and TEL1 in yeast cell cycle checkpoint pathways. Science 1996, 271:357-360.

51. Rose MD, Winston F, Hieter P: Methods in Yeast Genetics: a Laboratory Course Manual Cold Spring Harbor, N.Y.: Cold Spring Harbor, Laboratory; 1990.

52. Schiestl RH, Gietz RD: High efficiency transformation of intact yeast cells using single stranded nucleic acids as a carrier. Curr Genet 1989, 16:339-346.

53. Brachmann CB, Davies A, Cost GJ, Caputo E, Li J, Hieter P, Boeke JD: Designer deletion strains derived from Saccharomyces cerevisiae S288C: a useful set of strains and plasmids for PCR-mediated gene disruption and other applications. Yeast 1998, 14:115-132.

54. Eichinger DJ, Boeke JD: The DNA intermediate in yeast Ty1 element transposition copurifies with virus-like particles: cell-free Ty1 transposition. Cell 1988, 54:955-966

55. Monokian GM, Braiterman LT, Boeke JD: In-frame linker insertion mutagenesis of yeast transposon Ty1: mutations, transposition and dominance. Gene 1994, 139:9-18.

56. Keeney JB, Boeke JD: Efficient targeted integration at leu1-32 and ura4 294 in Schizosaccharomyces pombe. Genetics 1994, 136:849-856.

doi:10.1186/1759-8753-1-23

Cite this article as: O'Donnell et al:: Regulators of ribonucleotide reductase inhibit Ty1 mobility in saccharomyces cerevisiae. Mobile DNA $20101: 23$ 